\title{
Impact of the 4 April 2014 Saharan dust outbreak on the photovoltaic power generation in Germany
}

\author{
Daniel Rieger ${ }^{1, a}$, Andrea Steiner ${ }^{2}$, Vanessa Bachmann² ${ }^{2}$ Philipp Gasch ${ }^{1}$, Jochen Förstner ${ }^{2}$, Konrad Deetz $^{1}$, \\ Bernhard Vogel ${ }^{1}$, and Heike Vogel ${ }^{1}$ \\ ${ }^{1}$ Institute of Meteorology and Climate Research, Karlsruhe Institute of Technology, Hermann-von-Helmholtz-Platz 1, \\ 76344 Eggenstein-Leopoldshafen, Germany \\ ${ }^{2}$ Deutscher Wetterdienst, Frankfurter Str. 135, 63067 Offenbach, Germany \\ ${ }^{a}$ now at: Deutscher Wetterdienst, Frankfurter Str. 135, 63067 Offenbach, Germany
}

Correspondence to: Daniel Rieger (daniel.rieger@dwd.de)

Received: 11 May 2017 - Discussion started: 21 June 2017

Revised: 8 September 2017 - Accepted: 12 September 2017 - Published: 10 November 2017

\begin{abstract}
The importance for reliable forecasts of incoming solar radiation is growing rapidly, especially for those countries with an increasing share in photovoltaic (PV) power production. The reliability of solar radiation forecasts depends mainly on the representation of clouds and aerosol particles absorbing and scattering radiation. Especially under extreme aerosol conditions, numerical weather prediction has a systematic bias in the solar radiation forecast. This is caused by the design of numerical weather prediction models, which typically account for the direct impact of aerosol particles on radiation using climatological mean values and the impact on cloud formation assuming spatially and temporally homogeneous aerosol concentrations. These model deficiencies in turn can lead to significant economic losses under extreme aerosol conditions. For Germany, Saharan dust outbreaks occurring 5 to 15 times per year for several days each are prominent examples for conditions, under which numerical weather prediction struggles to forecast solar radiation adequately. We investigate the impact of mineral dust on the PV-power generation during a Saharan dust outbreak over Germany on 4 April 2014 using ICON-ART, which is the current German numerical weather prediction model extended by modules accounting for trace substances and related feedback processes. We find an overall improvement of the PV-power forecast for $65 \%$ of the pyranometer stations in Germany. Of the nine stations with very high differences between forecast and measurement, eight stations show an improvement. Furthermore, we quantify the direct radiative effects and indirect radiative effects of mineral dust.
\end{abstract}

For our study, direct effects account for $64 \%$, indirect effects for $20 \%$ and synergistic interaction effects for $16 \%$ of the differences between the forecast including mineral dust radiative effects and the forecast neglecting mineral dust.

\section{Introduction}

Renewable energy such as wind and solar power is gaining importance for the energy supply of many areas of the world. For example, in Germany renewable energy currently contributed up to $32.3 \%$ in 2016 to the gross electricity consumption, of which the contribution of solar energy is $6.5 \%$ (AGEE-Stat, 2016). Instantaneously, solar power can even cover up to $50 \%$ of Germany's electricity demand (Wirth, 2017). Weather-dependent renewable energy, such as photovoltaic (PV) power, poses a particular challenge to transmissions system operators (TSOs) and forecast providers because power production forecasts are afflicted with errors. A summary of the diverse state-of-the-art methods and related challenges in PV-power forecasting is given in Inman et al. (2013). For time horizons of hours to days, numerical weather prediction (NWP) models deliver the basis for PV-power predictions. Forecast errors arise during weather situations or phenomena that are insufficiently represented in NWP models (for PV power see Köhler et al., 2017). Large errors in the power forecast for weather-dependent renewables even endanger the stability of the electricity grid. To avoid power outages, the German TSOs need to take costly 
redispatch measures, which are short-term changes to the operating schedule of power plants. From 2014 to 2015, the gross electricity generation from wind and solar energy increased by $15 \%$ (AGEE-Stat, 2016); the redispatch volume, however, tripled (Bundesnetzagentur, 2016). Ultimately, the related costs are added to the household electricity prices. To guarantee a reliable and economic integration of increasing shares of renewables, there is a strong demand in the energy market to provide the most accurate PV-power forecasts possible (e.g., Lew and Richard, 2010; Lew et al., 2010). Driven by the growth of renewable energy shares in electricity production, the accuracy of solar NWP and power forecasts has to meet increasing standards. Additionally, the literature in this field of application is growing, although it is still a new area of research.

Solar radiation is modified by the clouds and aerosols in the atmosphere before reaching the solar panels. Aerosol particles interact with radiation by scattering and absorption (direct effect). They also change the physical properties of clouds, such as effective radii and droplet number concentration, which also modifies the radiation reaching the ground (indirect effect). Mineral dust is a prominent aerosol species in the atmosphere (Knippertz and Stuut, 2014), with global estimates for the mineral dust emissions ranging from 1000 to $5000 \mathrm{Tg} \mathrm{a}^{-1}$ (Shao et al., 2011). Mineral dust can be transported large distances from the source area, for example from the Sahara to Europe (Vautard et al., 2005; Pérez et al., 2006; Klein et al., 2010; Papayannis et al., 2008; Hande et al., 2015).

Current operational NWP models are unable to account for the effect of mineral dust during such episodes because they rely on aerosol climatologies. Nikitidou et al. (2014) investigated the spatial and temporal variability of aerosols over Europe and stressed the necessity for near-real-time forecasts of aerosol loads instead of climatological values. In areas of high desert-dust intrusions or intense anthropogenic activities, the reduction of direct normal irradiance (DNI) was found to reach values of up to 35 and $45 \%$, corresponding to 4 and $6 \mathrm{kWh} \mathrm{m}^{-2}$ day $^{-1}$. Recently, Casado-Rubio et al. (2017) showed that considering prognostic dust aerosol considerably improves DNI forecasts in Spain and the Canary Islands, which is of great importance for concentrating solar power. These findings are supported by the study of Schroedter-Homscheidt et al. (2016), who apply an interactive aerosol scheme for clear-sky cases. Gleeson et al. (2016) highlight the importance of using accurate aerosol concentration, optical properties and an accurate vertical distribution of aerosols in NWP forecasts of shortwave radiative fluxes in case of a wildfire. Concerning mineral dust, Bangert et al. (2012) have shown a significant potential to improve the surface temperature forecasts during a strong Saharan dust event over southern Germany when dust as well as direct and indirect effects are considered in the NWP system COSMO-ART (COnsortium for Small-scale MOdeling - Aerosol and Reactive Trace gases). For solar energy applications, however, it is of great importance to consider the influence on ground level radiation by dust aerosols (Breitkreuz et al., 2009; Zaihidee et al., 2016).

Since recent research has shown the importance of meteorology and aerosol or chemistry feedback in many research areas, many online-coupled mesoscale meteorology atmospheric chemistry models have been developed. Baklanov et al. (2014) give an extensive overview of such models in Europe. Considering prognostic aerosols and the interactions with the atmosphere in NWP models is costly in terms of computing time. However, thanks to the increase in computing power, there are several modeling systems worldwide providing daily forecasts of mineral dust distributions. Table 1 provides an overview on current operational mineral dust forecasting models. A more detailed description of available daily mineral dust forecasts and activities in this research area can be found at the World Meteorological Organization (WMO).

A quantitative example of solar energy reduction due to mineral dust is given by Calinoiu et al. (2013). For five dust episodes in Romania, a reduction in collectable PV power of 6.5 to $17.5 \%$ was reported. Perry and Troccoli (2015) investigated a controlled fire burn in Canberra, Australia, and indicated an overall PV-power reduction of $7 \%$ during the study period and a peak reduction of $27 \%$. Besides a more accurate radiation forecast, operational dust forecasts also provide the possibility to account for the deposition of dust on PV panels and for better maintenance planning. For a review on energy yield losses by dust deposition see Sayyah et al. (2014).

Within this paper, the focus is on the beginning of April 2014, when central Europe was influenced by an intensive Saharan dust outbreak. At the same time, large errors in the day-ahead forecasts of PV-power production challenged Germany's electrical grid management. On 4 April 2014, the day-ahead PV-power forecast overestimated the actual power production for Germany by up to $5.3 \mathrm{GW}$ (European Energy Exchange AG, 2017). The transport of mineral dust and its influence on atmospheric composition and radiation are not explicitly considered within conventional numerical weather prediction. Although it is speculated that these events have a large impact on PV production over Europe, a quantitative assessment is currently not available. In this study we use ICON-ART (ICOsahedral Nonhydrostatic - Aerosol and Reactive Trace gases; Rieger et al., 2015) to assess and quantify the effect of the Saharan dust outbreak in April 2014 on PVpower production. We will address the following questions in detail:

- What is the quantitative impact of mineral dust on simulated surface radiation and PV power?

- What is the contribution of the direct aerosol effect on radiation in comparison to effects caused by modifications of clouds? 
Table 1. Overview on operational mineral dust forecasting models.

\begin{tabular}{|c|c|c|}
\hline Model name & Institution & References \\
\hline BSC-DREAM8b & $\begin{array}{l}\text { Barcelona Supercomputing Cen- } \\
\text { ter }\end{array}$ & Pérez et al. (2006), Basart et al. (2012) \\
\hline NMMB/BSC-Dust & $\begin{array}{l}\text { Barcelona Supercomputing Cen- } \\
\text { ter }\end{array}$ & Pérez et al. (2011), Haustein et al. (2012) \\
\hline DREAM8-NMME-MACC & $\begin{array}{l}\text { South East European Virtual } \\
\text { Climate Change Center }\end{array}$ & Nickovic et al. (2001), Pérez et al. (2006) \\
\hline LOTOS-EUROS & $\begin{array}{l}\text { The Netherlands Organisation } \\
\text { for Applied Scientific Research }\end{array}$ & Manders-Groot et al. (2016), Manders et al. (2017) \\
\hline SKIRON & University of Athens & Spyrou et al. (2010) \\
\hline CAMS & $\begin{array}{l}\text { European Centre for Medium- } \\
\text { Range } \\
\text { Weather Forecasts }\end{array}$ & Morcrette et al. (2009), Benedetti et al. (2009) \\
\hline Met Office UM & UK Met Office & Woodward (2001), Woodward (2011) \\
\hline NGAC & $\begin{array}{l}\text { National Centers for Environ- } \\
\text { mental Prediction }\end{array}$ & Lu et al. (2016) \\
\hline GEOS-5 & $\begin{array}{l}\text { National Aeronautics and Space } \\
\text { Administration }\end{array}$ & Nowottnick et al. (2011) \\
\hline
\end{tabular}

Section 2 provides an overview of the modeling system ICON-ART. In particular, the new emission scheme for mineral dust, aerosol-radiation, aerosol-cloud and cloudradiation interactions are explained. The method to calculate PV power is outlined as well. Section 3 summarizes the synoptic situation during the Saharan dust outbreak and Sect. 4 describes the model setup. In Sect. 5, the results are presented, followed by the conclusions.

\section{Model description}

For this study, we use the online-coupled modeling system ICON-ART. The host model ICON is jointly developed by the German Weather Service (DWD) and the Max Planck Institute for Meteorology (MPI-M). ICON features a nonhydrostatic dynamical core and physical parameterization packages for numerical weather prediction, global climate modeling and for large eddy simulations (Zängl et al., 2015; Dipankar et al., 2015; Heinze et al., 2017). The governing equations of ICON are discretized on a triangular mesh offering an intuitive way of grid refinement by performing bisections of the triangles. This enables the possibility of incorporating further nests with two-way interactions within one simulation. In the NWP configuration, ICON is used as a global model for numerical weather prediction by DWD since January 2015 on a so-called R3B07 grid, i.e., with $13 \mathrm{~km}$ effective horizontal grid spacing. In July 2015, an R3B08 nest was added over Europe with $7 \mathrm{~km}$ effective horizontal grid spacing. Hence, ICON in its NWP configuration is continuously validated by the DWD. A further highlight of ICON is the high scalability and, therefore, high efficiency of modern computer architectures. Very important for the extended
Table 2. Parameters for the log-normally distributed mineral dust. $\bar{d}_{0, l, E}\left(\bar{d}_{3, l, E}\right)$ is the median diameter of the specific number (mass) emission of mode $l$. The SD of mode $l, \sigma_{l}$, is held constant for the whole simulation.

\begin{tabular}{lccc}
\hline & Dust mode A & Dust mode B & Dust mode C \\
\hline $\bar{d}_{0, l, E}(\mu \mathrm{m})$ & 0.6445 & 3.454 & 8.672 \\
$\bar{d}_{3, l, E}(\mu \mathrm{m})$ & 1.5 & 6.7 & 14.2 \\
$\sigma_{l}$ & 1.7 & 1.6 & 1.5 \\
\hline
\end{tabular}

modeling system ICON-ART is the local mass conservation and the mass-consistent tracer transport featured by ICON.

The ART extension is developed at the Karlsruhe Institute for Technology (KIT) with the goal to describe the spatiotemporal evolution of atmospheric trace substances and their associated atmospheric feedback processes. A detailed overview of the governing equations and the coupling concept of ICON-ART is given by Rieger et al. (2015). Mineral dust aerosol is described by three log-normally distributed modes with prognostic specific numbers and mass mixing ratios. The standard deviations (SDs) are kept constant during the simulation, making the median diameters diagnostic variables which can change during transport. The initial median diameters and the SDs are listed in Table 2. Sedimentation, dry deposition and washout of mineral dust are parameterized as described in Rieger et al. (2015), while coagulation and chemical aging are neglected. The emission of mineral dust and the interactions with radiation and clouds are explained in the following. 


\subsection{Emission of mineral dust}

We have implemented the mineral dust emission scheme of Vogel et al. (2006) improved by the following benefits. (1) It is based on a global dataset of soil properties (size distribution, residual soil moisture). (2) It accounts for the soil dispersion state. (3) A tile approach was introduced to account for soil type heterogeneity at coarse resolutions. The Vogel et al. (2006) scheme combines the parameterization of White (1979) for the saltation flux with a parameterization of Shao and $\mathrm{Lu}$ (2000) for the threshold friction velocity. When the friction velocity is above this threshold, soil erosion by wind is initiated. The resulting saltation flux is then used to calculate a dust emission flux using the parameterization of Alfaro and Gomes (2001). The size distribution of the emitted mineral dust varies according to soil type and meteorological situation.

The size distributions of soil particles are crucial input parameters for the mineral dust emission scheme. In order to obtain a global coverage, HWSD data (Harmonized World Soil Database; Nachtergaele and Batjes, 2012) containing the global distribution of soil types are used. For each of these soil types, two limiting particle size distributions, each consisting of up to four log-normal distributions, are used (see Table B1 in Shao et al., 2010). The following approach to calculate dust emission fluxes applies for one single soil type. For a grid box containing different soil types, a tile approach is used and explained afterwards.

For the size distribution of soil particles $n_{\mathrm{s}}\left(d_{\mathrm{p}}\right)$ we take the soil dispersion state into account. This can be described with the help of two limiting size distributions for weak erosion $n_{\mathrm{s}, \mathrm{m}}$ (minimally dispersed) and strong erosion $n_{\mathrm{s}, \mathrm{f}}$ (fully dispersed), in which the dispersion factor $\gamma_{\mathrm{d}}$ (between 0 and 1) determines the actual size distribution between the two limits depending on the friction velocity $u_{*}$ (Shao, 2001):

$n_{\mathrm{s}}\left(d_{\mathrm{p}}\right)=\gamma_{\mathrm{d}} \cdot n_{\mathrm{s}, \mathrm{m}}\left(d_{\mathrm{p}}\right)+\left(1-\gamma_{\mathrm{d}}\right) \cdot n_{\mathrm{s}, \mathrm{f}}\left(d_{\mathrm{p}}\right)$,

$\gamma_{\mathrm{d}}=e^{-0.5 \cdot\left(u_{*}-u_{* t, \mathrm{~m}}\right)^{3}}$.

$u_{* \mathrm{t}, \mathrm{m}}$ is the global minimum (in a mathematical sense) of the threshold friction velocity $u_{* \mathrm{t}}\left(d_{\mathrm{p}}\right)$. The threshold friction velocity is defined as the value of the friction velocity at an equilibrium of aerodynamic, cohesive and gravitational forces (e.g., Marticorena and Bergametti, 1995; Shao and Lu, 2000). For values higher than the threshold friction velocity, emission of soil particles takes place. Shao and Lu (2000) derive an expression for the threshold friction velocity from the equilibrium of moments of forces acting on the particle:

$u_{* \mathrm{t}}\left(d_{\mathrm{p}}\right)=f_{\mathrm{r}} \cdot f_{\eta} \cdot \sqrt{A_{n} \cdot\left(\frac{\rho_{\mathrm{s}}}{\rho} \cdot g \cdot d_{\mathrm{p}}+\frac{\gamma_{n}}{\rho \cdot d_{\mathrm{p}}}\right)}$,

with $A_{n}=0.0123$ and $\gamma_{n}=3 \cdot 10^{-4} \mathrm{~kg} \mathrm{~s}^{-2} . \rho$ is the air density, $\rho_{\mathrm{s}}=2650 \mathrm{~kg} \mathrm{~m}^{-3}$ is the density of the soil and $g$ is the gravitational acceleration. For application in a global or regional model, we include correction factors to account for the effects of roughness elements $\left(f_{\mathrm{r}}\right)$ and soil moisture $\left(f_{\eta}\right)$ on $u_{* \mathrm{t}}$ (e.g., Shao, 2001). Applying Eq. (3), we can analytically derive the global minimum of the threshold friction velocity, which is needed in Eq. (2).

Independent of the size distribution, no emission is possible below $u_{* \mathrm{t}, \mathrm{m}}$. The factor to account for soil roughness elements is calculated using the expression of Raupach (1993). This correction term is based on the percentage of plant coverage $p_{\mathrm{p}}$, a variable which is typically available in atmospheric modeling systems:

$$
\begin{aligned}
\quad f_{\mathrm{r}} & =\sqrt{1-0.5 \cdot \lambda} \cdot \sqrt{1+0.5 \cdot 90 \cdot \lambda}, \\
\text { with } \quad \lambda & =-0.35 \cdot \ln \left(1-p_{\mathrm{p}}\right) .
\end{aligned}
$$

Higher soil moisture leads to increased adhesive forces between the soil particles. Therefore the threshold friction velocity increases for higher soil moisture. To consider this behavior, the correction term by Fécan et al. (1998) is used, which is based on gravimetric soil moisture in $\% \eta$ and the percentage clay content $p_{\mathrm{c}}$ of the soil:

$$
\begin{aligned}
f_{\eta} & =\sqrt{1+1.21 \cdot\left(\eta-\eta^{\prime}\right)^{0.68}}, \\
\text { with } \quad \eta^{\prime} & =a_{z} \cdot\left(0.0014 \cdot p_{\mathrm{c}}^{2}+0.17 \cdot p_{\mathrm{c}}\right),
\end{aligned}
$$

where $\eta^{\prime}$ is a minimum value of $\eta$. The factor $a_{z}=5$ is introduced to account for too-high soil moisture content in the model (Zender et al., 2003) and to increase the performance of the emission scheme within ICON-ART. The derivation of $p_{\mathrm{c}}$ is explained in more detail at the end of this section. The saltation flux is calculated following White (1979):

$$
\begin{gathered}
F_{h}\left(d_{\mathrm{p}}\right)=C_{\text {white }} \cdot \frac{\rho}{g} u_{*}^{3} \cdot\left(1+\frac{u_{* \mathrm{t}}\left(d_{\mathrm{p}}\right)}{u_{*}}\right) \\
\left(1-\frac{u_{* \mathrm{t}}^{2}\left(d_{\mathrm{p}}\right)}{u_{*}^{2}}\right),
\end{gathered}
$$

where $C_{\text {white }}=0.7$ is a linear scaling parameter to adapt the dust emission flux to measurements. The total saltation flux $F_{\text {th }}$ is the result of an integration over all saltation particle diameters weighted by the product of the cross-sectional area and the number of particles (Vogel et al., 2006). This weighting represents the contribution of particle surface area at a certain diameter to the total soil surface area:

$$
\begin{aligned}
& F_{\text {th }}=f r_{\mathrm{e}} \cdot \sum_{s=1}^{4} \int_{-\infty}^{\infty} F_{h}\left(d_{\mathrm{p}}\right) \\
& \cdot \frac{\frac{\pi}{4} d_{\mathrm{p}}^{2} \cdot n_{\mathrm{s}}\left(d_{\mathrm{p}}\right)}{\int_{-\infty}^{\infty} \frac{\pi}{4} d_{\mathrm{p}}^{2} \cdot n_{\mathrm{s}}\left(d_{\mathrm{p}}\right) \mathrm{d} \ln d_{\mathrm{p}}} \mathrm{d} \ln d_{\mathrm{p}} .
\end{aligned}
$$

In contrast to Vogel et al. (2006), $n_{\mathrm{s}}\left(d_{\mathrm{p}}\right)$ takes into account the soil dispersion state by using Eq. (1). The summation is 
performed for the four log-normal size distributions of soil particles as described above. $f r_{\mathrm{e}}$ is the fraction of erodible soil calculated based on GlobCover2009 land use data (Arino et al., 2008). The fractions $f r_{b, i}$ of the land use classes - bare areas, sparse vegetation, closed to open grassland, closed to open shrubland and mosaic grassland/forest-shrubland - sum up to the erodible fraction $f r_{\mathrm{e}}=\sum_{i=1}^{5} f r_{b, i}$.

By impaction of the saltating particles, the saltation flux leads to the release of small particles creating a dust emission flux. Alfaro and Gomes (2001) use the kinetic energy of the impaction, which has to exceed the binding energies of particles in the soil to describe this process. Larger particles are less tightly bound to the soil, and hence their binding energy is smaller than that of smaller particles. This leads to the following equation that connects the saltation flux with the dust emission flux of aerosol mode $l$ (Alfaro and Gomes, 2001):

$F_{\mathrm{v}, l}\left(d_{\mathrm{p}}\right)=\frac{\pi}{6} \cdot \rho_{\mathrm{p}} \cdot d_{3, l}^{3} \cdot \frac{p_{l}\left(d_{\mathrm{p}}\right) \cdot \beta_{\mathrm{kin}} \cdot F_{h}\left(d_{\mathrm{p}}\right)}{e_{l}}$,

with $\beta_{\text {kin }}=163 \mathrm{~m} \mathrm{~s}^{-2}$. The product $\beta_{\text {kin }} \cdot F_{h}\left(d_{\mathrm{p}}\right)$ is the kinetic energy of the saltation particles and $e_{l}$ the binding energy of particles of mode $l . p_{l}$ is the percentage of kinetic energy that is spent to release particles of mode $l$ and is calculated based on the binding energies as summarized in Table 2 of Alfaro and Gomes (2001). These percentages of kinetic energy are chosen such that particles in the largest mode are emitted first when the threshold friction velocity is exceeded. With increasing friction velocity, the share of smaller particles that are released increases. An integration of Eq. (10) over all saltation particle diameters weighted by their crosssectional areas yields the total dust emission flux of mode $l$ :

$$
\begin{gathered}
F_{\mathrm{tv}, l}=f r_{e} \cdot \sum_{s=1}^{4} \int_{-\infty}^{\infty} F_{\mathrm{v}, l}\left(d_{\mathrm{p}}\right) \\
\cdot \frac{\frac{\pi}{4} \cdot d_{\mathrm{p}}^{2} \cdot n_{\mathrm{s}}\left(d_{\mathrm{p}}\right)}{\int_{-\infty}^{\infty} \frac{\pi}{4} \cdot d_{\mathrm{p}}^{2} \cdot n_{\mathrm{s}}\left(d_{\mathrm{p}}\right) \mathrm{d} \ln d_{\mathrm{p}}} \mathrm{d} \ln d_{\mathrm{p}}
\end{gathered}
$$

Similar to the saltation flux, $n_{\mathrm{s}}\left(d_{\mathrm{p}}\right)$ takes the soil dispersion state into account (Eq. 1). Equation (11) was derived for one specific soil type. As ICON-ART is typically used with grid spacings ranging from $10^{0}$ to $10^{2} \mathrm{~km}$, a grid box may contain a mixture of different soil types. To account for this subgrid-scale heterogeneity, a tile approach is introduced.

The size distributions of soil particles from Shao et al. (2010) are available for soil types as defined by the US Department of Agriculture (USDA) except for silt, where silty loam is used instead. Table 3 provides an overview of the soil types and the percentaged clay content $p_{\mathrm{c}, i}$ of soil type $i$. To determine the soil type in an ICON-ART grid element, information from the high-resolution (30 arc seconds) global database HWSD (Nachtergaele and Batjes, 2012) is aggregated to the target grid. By this, the fraction $f_{\mathrm{s}, i}$ covered by
Table 3. Clay content assumed for the USDA soil types.

\begin{tabular}{ccc}
\hline USDA name & Abbreviation & $p_{\mathrm{c}, i}$ \\
\hline Heavy clay & HCLA & $100 \%$ \\
Light clay & LCLA & $80 \%$ \\
Silty clay & SILC & $50 \%$ \\
Sandy clay & SCLA & $45 \%$ \\
Silty clay loam & SICL & $30 \%$ \\
Clay loam & CLOA & $30 \%$ \\
Sandy clay loam & SCLO & $30 \%$ \\
Loam & LOAM & $15 \%$ \\
Silt loam & SILO & $10 \%$ \\
Sandy loam & SLOA & $10 \%$ \\
Silt & SILT & $5 \%$ \\
Loamy sand & LSAN & $5 \%$ \\
Sand & SAND & $5 \%$ \\
\hline
\end{tabular}

soil type $i$ with $\sum_{i=1}^{14} f_{\mathrm{s}, i}=1$ is available to the model. There are 14 fractions as, in addition to the 13 soil types, 1 fraction accounting for water, rock and urban surfaces is considered. As stated previously, a tile approach is used to calculate the dust emission flux. For clarity, Eq. (11) was derived for one single soil type $i$. To consider the subgrid-scale heterogeneity of soil properties, the dust emission fluxes $F_{\mathrm{tv}, l, i}$ are calculated for each soil type separately and the result is then weighted with the corresponding fraction of the soil to get the final dust emission flux:

$F_{\mathrm{tv}, l}=\sum_{i=1}^{13} f_{\mathrm{s}, i} \cdot F_{\mathrm{tv}, l, i}$.

The soil clay content used in Eq. (7) to calculate the residual soil moisture content in a grid element can be calculated with

$p_{\mathrm{c}}=\sum_{i=1}^{13} f_{\mathrm{s}, i} \cdot p_{\mathrm{c}, i}$

The calculation of dust emission fluxes $F_{\mathrm{tv}, l, i}$ for individual soil types within one grid element differs by the use of the individual soil particle size distributions $n_{\mathrm{s}, i}\left(d_{\mathrm{p}}\right)$. However, it differs neither in the clay content of the soil within one grid element nor in the residual soil moisture $\eta^{\prime}$. The simple reason for this is that the gravimetric soil moisture $\eta$ used from the surface scheme of ICON-ART is a grid-scale variable and hence is the average value for one grid element. As Eq. (6) includes a difference between $\eta$ and $\eta^{\prime}$, grid-scale values for both variables are used.

\subsection{Radiation}

ICON-ART includes online mineral dust-radiation interaction utilizing the Rapid Radiative Transfer Model (RRTM) 
(Mlawer et al., 1997) as described in more detail by Gasch et al. (2017). To account for the influence of mineral dust on radiation, the optical properties of mineral dust are calculated offline once. For this, Mie calculations are applied, which require the complex refractive index of mineral dust (Mie, 1908) as input. For the Mie calculations, a code developed by Bond et al. (2006) was used. This code in turn utilizes a subset developed by Mätzler (2002) for the calculation of the scattering coefficients and truncation of the series. The code was adapted to allow for processing of multiple wavelengths and averaging to the RRTM wavebands in a post-processing step. A new polynomial parameterization was introduced to account for the change in median diameter during transport. The local radiative transfer parameters (extinction coefficient, single scattering albedo and asymmetry parameter) are then calculated online within ICON-ART through multiplication of the mass-specific mineral dust optical properties derived from Mie calculations with the current mineral dust mass concentration from ICON-ART. The actual radiative transfer parameters are then used by the RRTM radiation scheme, thereby accounting for the local mineral dust effect on radiation. Thus, changed radiative fluxes from the RRTM scheme feedback on the meteorological conditions, which themselves can influence the mineral dust processes again.

The values of the refractive index of mineral dust used for the Mie calculations are of great importance for the radiative properties extinction coefficient, single scattering albedo and asymmetry parameter. Highwood and Ryder (2014) give a summary of the various influences. For example, peaks in the real part show as maxima of the extinction coefficient, whereas the single scattering albedo and thereby absorption is determined by the imaginary part of the refractive index.

In order to assess the uncertainties related to the refractive indices we have conducted a sensitivity study. The data sources used for the refractive indices are shown in Table 4 and the values for the real part and the imaginary part of the refractive index are presented in Fig. 1. The refractive indices used in ICON-ART (BUSE) are the same as those used by Stanelle et al. (2010) for COSMO-ART.

For the longwave part of the spectrum down to $4 \mu \mathrm{m}$ we use values as published by Helmert et al. (2007). For wavelengths smaller than $4 \mu \mathrm{m}$ the shape of the Helmert et al. (2007) curve is still replicated, however, with a fit through smaller values for the imaginary part which are obtained from Petzold et al. (2009). This part of the spectrum is especially important as solar radiation intensity is highest at these wavelengths. The smaller values correspond to weaker absorptive and enhanced scattering properties of mineral dust in ICON-ART for this part of the spectrum. These smaller values are in better agreement with Dubovik et al. (2002), who by inversion of AERONET (AErosol RObotic NETwork) retrievals determined values similar to Petzold et al. (2009). This is further supported by several studies: Moulin et al. (2001) report inconsistencies between popular dust models and remote measurements due to uncertainties in the imaginary part of the refractive index. Balkanski et al. (2007) show a better representation of observed mineral dust radiative forcing in models using these refractive indices obtained from AERONET, confirming that mineral dust is less absorptive than previously thought. Kaufman et al. (2001) point out that in situ measurements reporting higher absorption values possibly measured a mixture of dust and absorbing aerosol. McConnell et al. (2010) obtained imaginary part refractive index values similar to those used in ICON-ART.

The data presented in Fig. 1 exhibit a large scatter of the refractive indices. This has to be considered alongside other sources of uncertainty, such as the size distribution of the dust particles. To account for these uncertainties, we conducted Mie calculations for the refractive indices differing most from the ones we are using (Fig. 2a), namely that of Volz (1972) and Köpke et al. (1997), as well as for varying median diameters of the log-normal distribution of the dust particles (Fig. 2b). The results show that changes in the size distribution lead to a stronger signal than changes in the refractive index. This is in agreement with findings of Myhre and Stordal (2001).

A recent study by Di Biagio et al. (2017) provides the first regionally detailed values of refractive indices for the longwave part of the spectrum. Although for the direct effect of mineral dust on the PV-power forecast the shortwave part of the spectrum is of greater importance, a usage of this dataset can lead to changes in the mineral dust radiative effect on meteorological conditions and to a further improvement of the forecast.

\subsection{Aerosol-cloud interactions}

In the operational version of ICON used at DWD, a bulk scheme is applied to treat the cloud microphysical processes. For this study, we are using the two-moment microphysics scheme of Seifert and Beheng (2006). This scheme solves prognostic budget equations for number and mass concentrations of six hydrometeor classes (cloud, rain, ice, snow, graupel, hail). For the size distribution of hydrometeors, generalized gamma distributions with constant shape parameters are used. It considers the microphysical processes of autoconversion, accretion, self-collection and breakup in the warm phase. For cold clouds, diffusional growth, freezing, aggregation, self-collection, riming and melting are taken into account.

For the nucleation of ice particles, a competition between heterogeneous and homogeneous freezing occurs. Homogeneous freezing describes the formation of an ice particle without the involvement of a solid ice nucleus (IN). It takes place at temperatures below $235 \mathrm{~K}$ at high supersaturations with respect to ice on the order of 40 to $80 \%$. As this process does not depend on aerosol characteristics (Koop et al., 2000) and there are always sufficient liquid droplets available (e.g., Köhler and Seifert, 2015), a large number of ice 
Table 4. Overview of studies determining mineral dust refractive indices.

\begin{tabular}{llllll}
\hline Publication & Characterization & Source & Collection & Waveband & Acronym \\
\hline Petzold et al. (2009) & SAMUM & Sahara & Aircraft & SW & SAM \\
Helmert et al. (2007) & Compilation & Various & - & SW, LW & HEL \\
Fouquart et al. (1987) & ECLATS & Sahara & Niamey, Niger & LW & FOU \\
Köpke et al. (1997) & GOADS Comp. & Various & - & SW, LW & KOE \\
Volz (1973) & & Sahara & Barbados & LW & SVO \\
Volz (1972) & Rain-out Dust & Various & USA & SW, LW & DVO \\
Dubovik et al. (2002) & AERONET & Various & Worldwide & SW & DUB \\
\hline
\end{tabular}
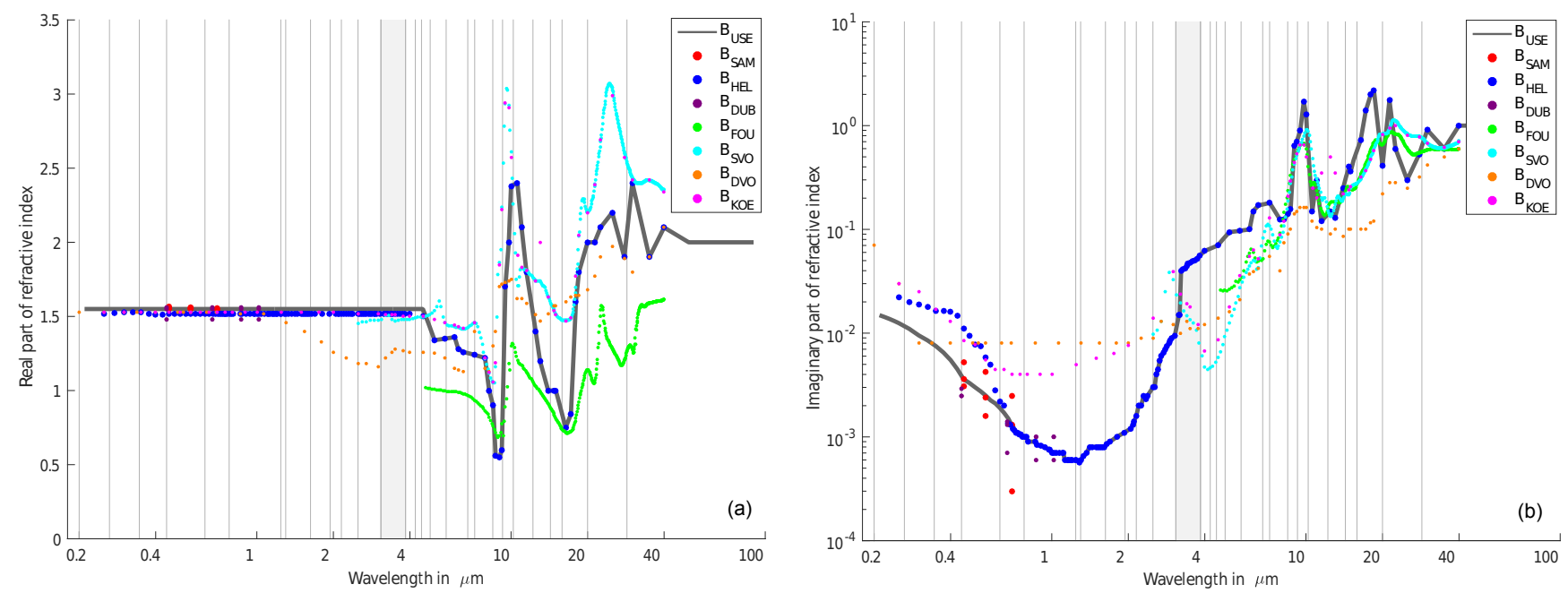

Figure 1. Real (a) and imaginary (b) part of refractive indices according to studies listed in Table 4 and used in ICON-ART ( $B_{\text {USE }}$ ). The borders of the RRTM radiation scheme wavebands are adumbrated as light grey lines in the background. The filled grey band represents the waveband present both in the longwave and shortwave part of the RRTM.

particles form nearly instantly as soon as these ambient conditions are met. In accordance with these assumptions, we set the number of liquid droplets available for homogeneous freezing to $1000 \mathrm{~cm}^{-3}$. This leads to a strong increase in water vapor depletion and therefore a fast decline of supersaturation, which in turn leads to small ice particles. Heterogeneous freezing occurs at surfaces of IN that grant favorable conditions for freezing. Depending on IN characteristics, heterogeneous freezing can even occur at temperatures close to $0{ }^{\circ} \mathrm{C}$ at ice saturation (for a review see Hoose and Möhler, 2012). Due to comparatively low concentrations of IN at heights where freezing occurs, the nucleation rate of pure heterogeneous freezing is typically 1 to 2 orders of magnitude lower than that of pure homogeneous freezing. Hence, the depletion of supersaturation takes longer and larger ice particles are formed. For ICON-ART, the empirical parameterization of Phillips et al. (2013) is used to describe heterogeneous formation of ice particles. In an ascending air parcel, heterogeneous freezing occurs earlier (i.e., at higher temperatures and lower supersaturation) than homogeneous freezing. Hence, a sufficient number of IN can suppress homogeneous freezing due to depletion of water vapor. To account for these competing mechanisms, ICON-ART uses the parameterization of Barahona and Nenes (2009). The resulting discrepancy in number concentration and size distribution of ice particles between the two freezing mechanisms leads to differences in the radiative properties of the clouds. Mineral dust is one of the most ubiquitous types of aerosol and acts as IN at temperatures as high as $-10^{\circ} \mathrm{C}$. Measurements show that other IN can usually be neglected for modeling studies (Cziczo et al., 2013).

The coupling of microphysics and the parameterization to account for competing effects of the freezing mechanisms was performed in a similar way to Bangert et al. (2012) and Bangert (2012) with two exceptions. The SD of the assumed subgrid-scale Gaussian distribution of the vertical velocity was reduced by a factor of 0.3 to $\sigma_{w}=0.3 \sqrt{\mathrm{TKE}}$, where TKE is the (prognostic) turbulent kinetic energy. The value of 0.3 was derived by tuning based on ML-CIRRUS measurements (Voigt et al., 2016). Additionally, a budget variable for mineral dust acting as IN was introduced to prevent double counting. We followed the approach of Köhler and Seifert (2015) by using a characteristic relaxation timescale of $4 \mathrm{~h}$ 

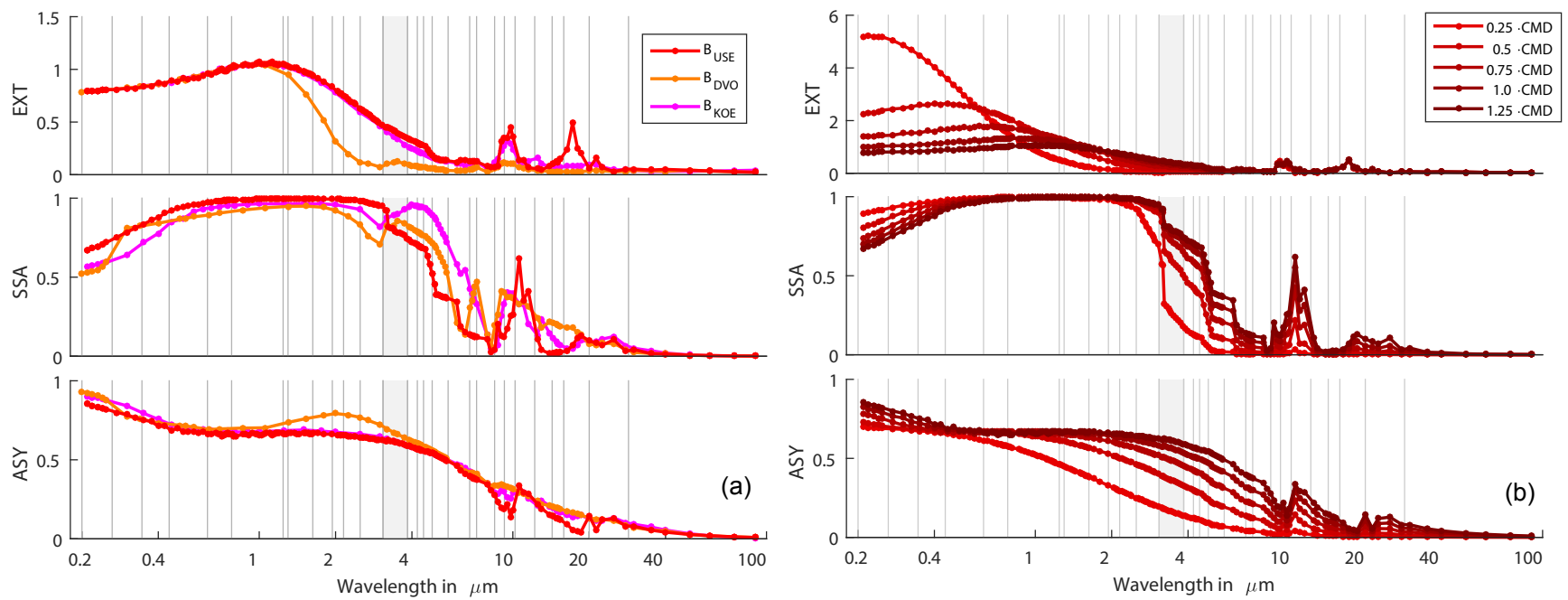

Figure 2. Influence of different refractive indices on the specific extinction coefficient (EXT) in $\mathrm{m}^{2} \mathrm{~g}^{-1}$, single scattering albedo (SSA) and asymmetry parameter (ASY) for mode A (a). Influence of varying count median diameter (CMD) on EXT, SSA and ASY for mode A (b).

in which only part of the mineral dust is available for further heterogeneous freezing.

\subsection{Clouds and radiation}

As mineral dust serves as ice nuclei in ICON-ART it modifies the physical properties of the simulated clouds. Consequently, the optical properties of the ice clouds are modified when mineral dust is present. The optical properties of the ice crystals are calculated according to Stevens et al. (2013) based on the cloud ice effective radius.

Since in the operational setup a one-moment scheme for the microphysical processes is used, the effective radii are calculated as a function of the ice mass concentration only. Instead, for this study, the ice particle size distribution obtained from the two-moment microphysics scheme of Seifert and Beheng (2006) is used. For the calculation of the ice particle effective radii, we apply the formula of Fu et al. (1998).

\subsection{PV-power calculation}

To calculate PV power we apply the open-source PV modeling environment PV_LIB for python (Andrews et al., 2014). It converts direct and diffuse radiation, temperature and wind speed into normalized PV power. Here the normalization is done with respect to the nominal capacity. Therefore, a specific PV module and PV inverter combination, as well as the module's tilt and orientation, need to be specified. Furthermore, the surface albedo and station height are necessary input parameters.

All evaluations concerning PV power presented in the following assume a south-oriented PV module with a nominal power of $220 \mathrm{~W}$ and a size of $1.7 \mathrm{~m}^{2}$. The chosen configuration represents a typical system for applications on residential or industrial rooftops in Germany. In more de-

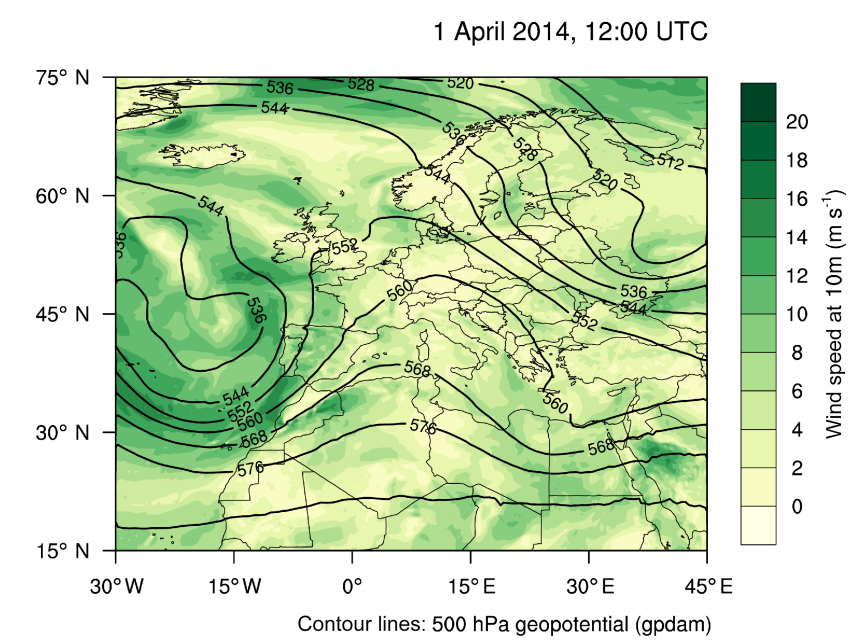

Figure 3. Large-scale synoptic situation on 1 April 2014, 12:00 UTC. Contour lines show the $500 \mathrm{hPa}$ geopotential field, and the wind speed at $10 \mathrm{~m}$ is depicted by colored shading. The fields are retrieved from a global $+12 \mathrm{~h}$ ICON-ART forecast with an effective grid spacing of $40 \mathrm{~km}$.

tail, a "Canadian Solar CS5P-220M" PV module and the micro-inverter "ABB: MICRO-0.25-I-OUTD-US-208" are selected. The software PV_LIB retrieves the corresponding module and inverter properties automatically from an online database provided by NREL (National Renewable Energy Laboratory of the US Department of Energy).

\section{Synoptic situation}

Figure 3 shows the large-scale synoptic situation that has led to the examined Saharan dust outbreak. The contour lines 


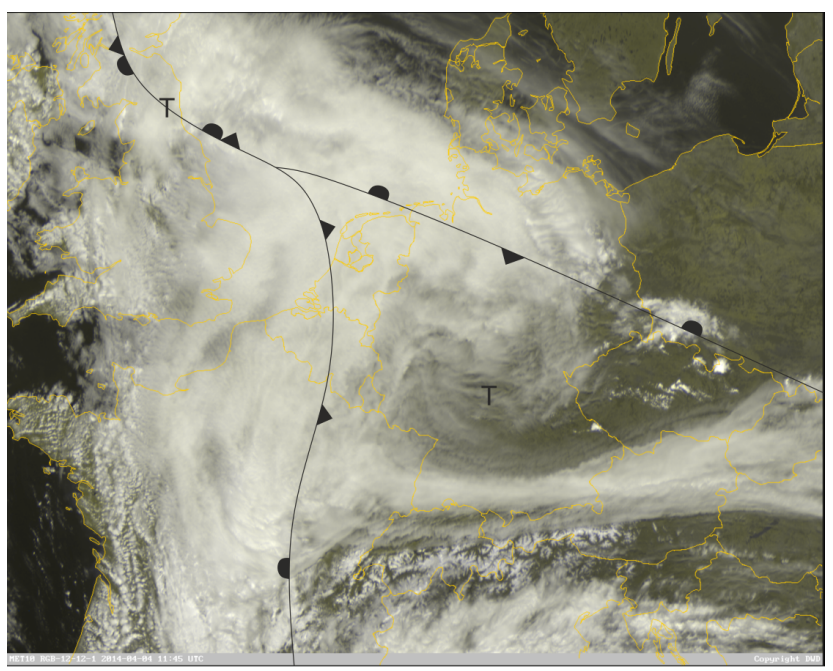

Figure 4. RGB composite of Germany and surrounding countries as observed by the Meteosat-10 satellite for 4 April 2014, 11:45 UTC. Frontal zones as analyzed by DWD based on surface observations for 4 April 2014, 12:00 UTC. Data source: EUMETSAT and DWD.

depict the $500 \mathrm{hPa}$ geopotential field and the color shading gives the wind speed at $10 \mathrm{~m}$ height. On 1 and 2 April 2014, a large part of Europe is influenced by a ridge, whereas a pronounced elongated trough lies over the eastern Atlantic. The situation represents a characteristic circulation pattern favorable for Saharan dust outbreaks, as identified by Flentje et al. (2015). As the axis of the Atlantic trough moves slowly eastwards, it affects northern Africa by supporting cyclogenesis along the border between Morocco and Algeria. This in turn favors higher wind speeds at the surface (see Fig. 3) and an intensified mineral dust emission. Emitted mineral dust is lifted and transported towards central Europe along the forward flank of the trough. Simulations suggest that the Saharan dust reaches France on 2 and 3 April, whereas Germany is affected mainly on the subsequent 2 days. On 4 and 5 April, extraordinarily large day-ahead PV-power forecast errors occurred. These days are amongst the 100 days with largest day-ahead PV-power forecast errors in Germany within 2013 and 2014 as analyzed by Köhler et al. (2017). Throughout this period, Germany remains under a weakening upper air ridge. Concurrently, the Atlantic trough develops into a cutoff low, which traverses the Mediterranean Sea. It transports Saharan dust over Italy towards southeastern Europe and the southern Alps. Only a little mineral dust is transported towards southern Germany by the cutoff low.

The following simulations concentrate on 4 April 2014. On that day, Germany, Benelux and northeastern France are located in the warm sector of an old, hardly moving frontal system (see Fig. 4). A thicker cloud layer influences northern Germany and a stationary cloud band is visible along the Alps. Throughout the day, light precipitation is observed in northwestern Germany as the warm front moves slowly

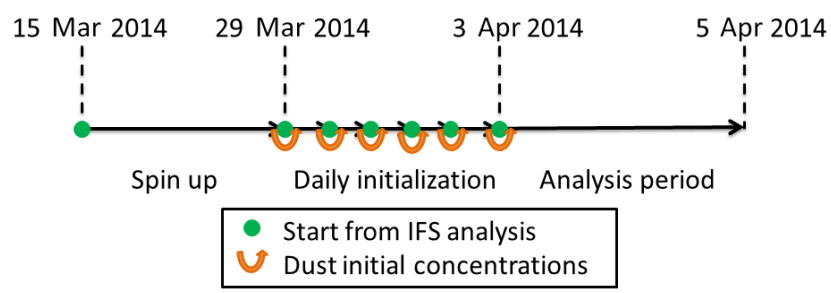

Figure 5. Schematic overview of the simulations that were performed as a preparation for the simulation of the analysis period.

Table 5. Simulations performed for this study and the mineral dust concentration used to calculate radiation and cloud microphysics.

\begin{tabular}{lll}
\hline Case name & Radiation & Cloud formation \\
\hline TT & Original concentration & Original concentration \\
FF & $0.1 \cdot$ concentration & $0.1 \cdot$ concentration \\
TF & Original concentration & $0.1 \cdot$ concentration \\
FT & $0.1 \cdot$ concentration & Original concentration \\
\hline
\end{tabular}

northward. Especially central and parts of southern Germany are influenced by high clouds. Even though high clouds subjectively appear transparent, they considerably reduce the incoming shortwave radiation. Additionally, Saharan mineral dust is present and reduces the transparency of the atmosphere as well. To achieve a good PV-power forecast it is essential to correctly forecast the diverse clouds on 4 April 2014, as well as the mineral dust particles in the atmosphere and their effects on radiative transfer.

\section{Model setup}

For our simulations, we are using a global R2B06 grid with an effective horizontal grid spacing of $40 \mathrm{~km}$. A nested R2B07 grid $(20 \mathrm{~km})$ is added covering source and target region, i.e., north Africa and central Europe. Further successive R2B08 and R2B09 nests cover central Europe with effective horizontal grid spacings of 10 and $5 \mathrm{~km}$. Our analysis is performed for the highest resolved nest with $5 \mathrm{~km}$ effective grid spacing. We are using ICON-ART in its NWP configuration with the corresponding package of physical parameterizations with the exceptions described above.

Figure 5 sketches the simulation procedure applied to provide the most realistic spatiotemporal distribution of mineral dust aerosol for 4 April 2014. A spinup simulation is started from ECMWF's (European Centre for MediumRange Weather Forecasts) Integrated Forecast System (IFS) analysis on 15 March 2014, 00:00 UTC, in order to generate background concentrations of mineral dust. This simulation runs free for 14 days. On 29 March, 00:00 UTC, a reinitialization is performed using the corresponding IFS analysis in combination with the mineral dust concentrations calculated by the spinup simulation. From 29 March until 3 April 
this procedure is repeated daily in order to accurately capture the emission and transport processes of the mineral dust in this important period. From 3 April 00:00 UTC onwards, the simulation is running free again with mineral dust feedback processes activated; i.e., no reinitialization is performed on 4 April 00:00 UTC, giving the clouds 1 day to adjust before an aerosol effect on clouds is analyzed.

As stated before, we are interested in the improvement of PV-power forecast due to a better representation of mineral dust concentrations and its impact on radiation in the model. A classical approach to quantify these differences would be to carry out two simulations, A and B. In case A, a climatological mineral dust distribution would be applied as it is done in operational weather forecast. In case B, the online-calculated mineral dust concentrations would be used instead. Subtracting the results of both simulations the effect of mineral dust on temperature and radiation could be quantified. However, this method suffers from several shortcomings. The spatial distribution of the simulated and the climatological concentrations may differ considerably. At some places the online-calculated concentrations might be higher than the simulated ones and vice versa. Thus, the effects of mineral dust on radiation and PV could not be quantified.

For this reason, we decided to choose a different approach for the reference simulation. We are using in all cases prognostically derived mineral dust concentrations. In the false case $(F)$, however, we assume a reduced impact on radiation and/or cloud formation, which is realized by a reduction of the mineral dust concentrations by a factor of 0.1 when used to calculate these processes. This results in the $2^{2}$ simulations summarized in Table 5 that we need for our analysis. Although the mineral dust horizontal, vertical and size distributions of the individual simulations differ slightly due to the feedback of radiation and cloud microphysics on the mineral dust distributions, the impact of this is negligible. Consequently, compared to the classical approach, this method has the advantages that (1) the location of extreme values agrees between the individual simulations and (2) there is no impact of different size distributions on the results.

\section{Results}

In the following, results of the simulations as well as thereof calculated PV-power forecasts are presented and evaluated.

\subsection{Simulated mineral dust distribution}

Mineral dust emitted from the Sahara during 1 and 2 April is transported towards central Europe along the forward flank of a trough. After being transported across France, it reaches Germany on the 4 April 2014. This can be seen in Fig. 6, which shows the spatial distribution of mineral dust optical depth at $500 \mathrm{~nm}$ (in the following abbreviated with AOD) at different dates. Already during the night of 4
April 2014, the southern part of Germany is covered by a mineral dust plume, which leads to an AOD between 0.25 and 1. Over France, higher values between 1 and 1.5 are simulated. During the day, the mineral dust is transported to the north so that in the evening all of Germany is affected by the mineral dust, with the highest AOD values of about 1 in the northwest. In the remaining parts the AOD values are between 0.25 and 0.5 .

A qualitative comparison to satellite, ceilometer and lidar observations shows that the spatial distribution and temporal evolution of mineral dust as simulated over Europe is in good agreement with the available measurements. Unfortunately, these observations of mineral dust are hampered by the presence of clouds. The areas with high mineral dust loads coincide also with cloudy conditions and only a few observation time steps within the period of interest are available for a quantitative comparisons. In Fig. 7, the mineral dust aerosol optical depth as forecasted at $20 \mathrm{~km}$ grid spacing for case TT is shown for 4 April 2014. On top of that, filled circles provide the corresponding AERONET measurements. The observations are averaged within a time interval of $1 \mathrm{~h}$ before target time and represent level 2 coarse-mode AOD at $500 \mathrm{~nm}$ (derived with Direct Sun Algorithm version 2 and Spectral Deconvolution Algorithm version 4.1; for a description see AERONET, 2017). The arrival of the dust cloud in eastern Germany is observed by the station Lindenberg. There is only a small spatial discrepancy with the forecasted location of the dust cloud. Note that the region with rapid increase of mineral dust concentration also visualizes the weak frontal zone spanning from the North Sea over eastern Germany to the southeast of Europe (see Sect. 3).

\subsection{Radiation}

The surface incoming shortwave irradiance (SIS, or global radiation) is the key parameter for adequate PV-power forecasts. In order to evaluate the numerical simulations we use in situ and remote sensing observations. Surface measurements of global radiation are available from SYNOP stations hourly and, with a temporal resolution of $1 \mathrm{~min}$, from the pyranometer network of the DWD. Additionally, the surface shortwave radiation as retrieved from the SEVIRI (Spinning Enhanced Visible and InfraRed Imager) sensor on board the geostationary METEOSAT (Meteorological satellite) second-generation (MSG) satellite number 10 is available for comparison with model results. In particular, hourly SARAH-2 data (Surface Solar Radiation Data records - Heliosat; Pfeifroth et al., 2017) are used, which are provided by the EUMETSAT (European Organisation for the Exploitation of Meteorological Satellites) Satellite Application Facility on Climate Monitoring (CM SAF). It should be noted that the retrieval algorithm for the SARAH-2 data employs a modified MACC (Monitoring Atmospheric Composition and Climate) aerosol climatology (Mueller et al., 2015), which 

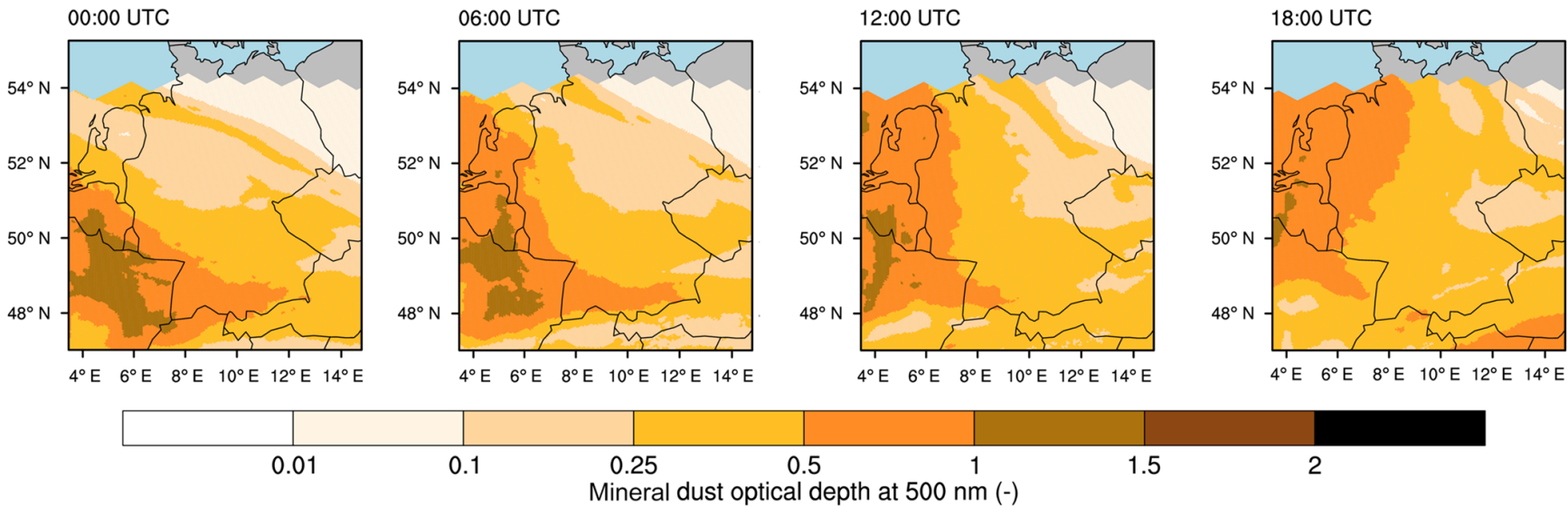

Figure 6. Mineral dust optical depth at $500 \mathrm{~nm}$ over Germany on 4 April 2014 at 00:00 UTC, 06:00 UTC, 12:00 UTC and 18:00 UTC (TT case). Note the saw-tooth shape in the northern part which marks the margin of the high-resolution $(5 \mathrm{~km})$ domain and must not be confused with mineral dust-free conditions.
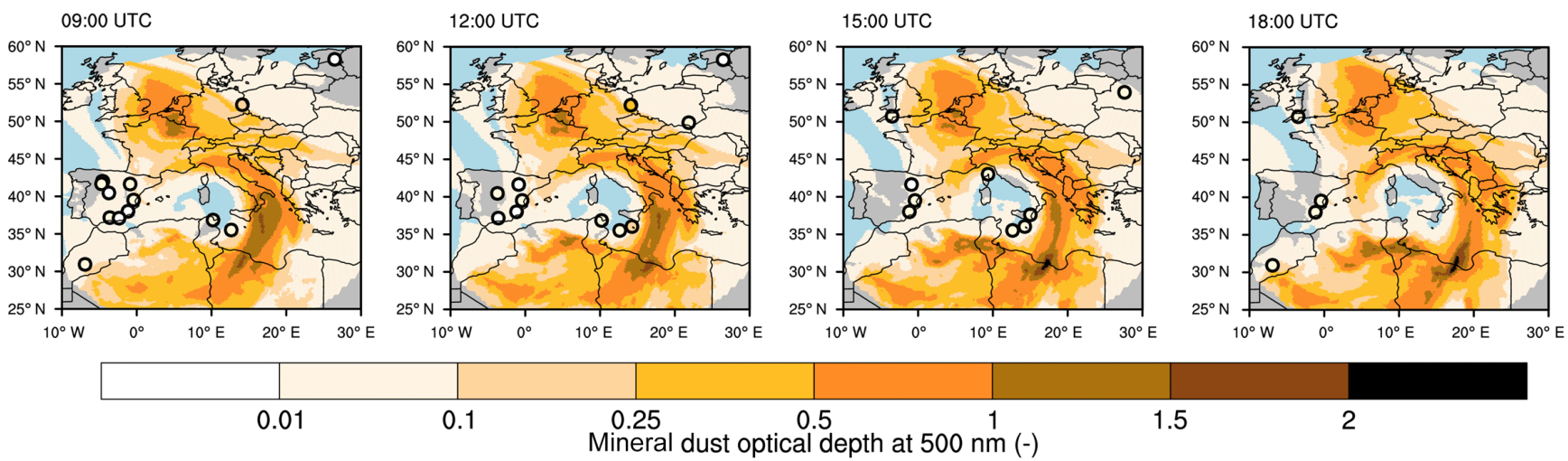

Figure 7. Mineral dust optical depth at $500 \mathrm{~nm}$ over Europe on 4 April 2014 at 09:00 UTC, 12:00 UTC, 15:00 UTC and 18:00 UTC (TT case) at $20 \mathrm{~km}$ grid spacing. The filled circles represent observations from AERONET stations. Note the saw-tooth shape next to the borders which marks the margin of nest R2B07 and must not be confused with mineral dust-free conditions.

deviates from the actual concentrations especially during mineral dust episodes. Therefore, the satellite-derived SIS can be expected to overestimate the real SIS in the considered time period.

Figure 8 shows the horizontal distribution of SIS for the simulations TT and FF and for the satellite product SARAH2 on 4 April 2014, 12:30 UTC. In addition to the simulation results, the SIS measured at SYNOP and pyranometer stations are depicted in circles. Pyranometer stations are indicated by bold circles. There are two main synoptic features that were not correctly captured by both numerical simulations. On the one hand, the cloud band along the Alps is missing (see Fig. 4). On the other hand, the activity of the frontal system in the northern part of Germany and the related clouds are represented in a different way (see Fig. 4). The cloud cover and corresponding precipitation is overestimated in eastern Germany, whereas the rainfall in northern Germany in the afternoon is underestimated (not shown). Such fine structures are challenging for day-ahead numerical weather predictions. Inherently, deterministic NWP forecasts are afflicted with errors. These arise from inaccurate initial conditions as well as from deficiencies in the NWP model, whereas small errors in the finer structure, such as the position of individual clouds, tend to grow more rapidly (Kalnay, 2003). Ensemble forecasts could provide an estimate of the reliability of the forecast and of individual synoptic patterns such as the discussed frontal system. However, this is not within the scope of this study, and we concentrate on the differences between the simulations TT and FF.

In the northern part of Germany both simulations show very low SIS values, which were also observed by the satellite and by the ground-based stations. In the western part, where the AOD reaches the highest values, simulation TT gives noticeably lower SIS than in case of simulation FF, which is in better agreement with the observations. These improvements can be attributed to the consideration of the interactions between mineral dust and meteorology. 
(a) $\mathrm{TT}$

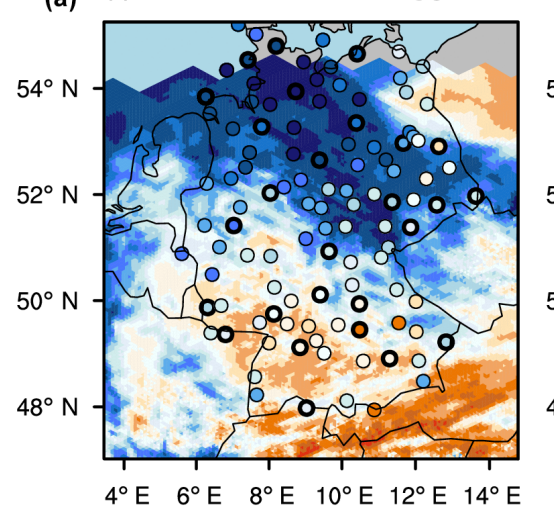

(b) FF

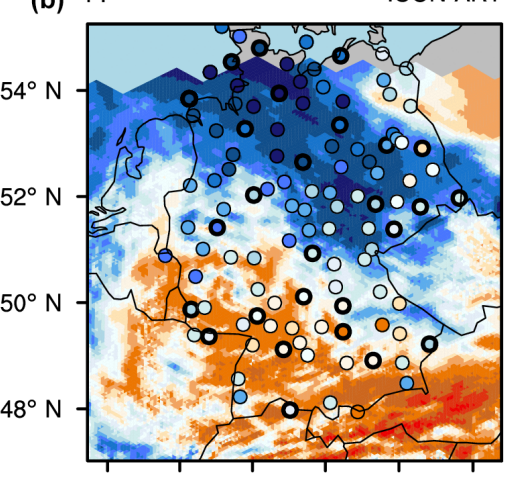

(c) SARAH-2

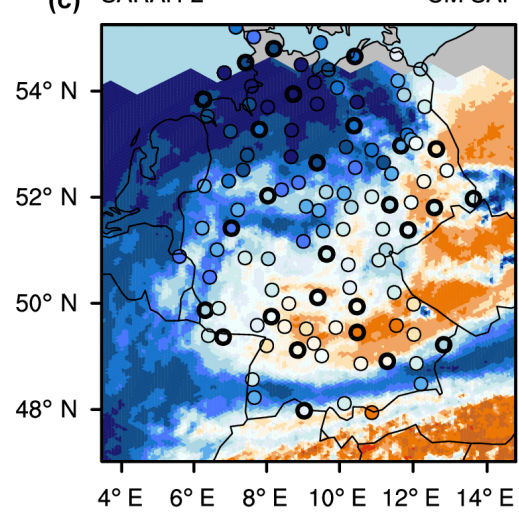

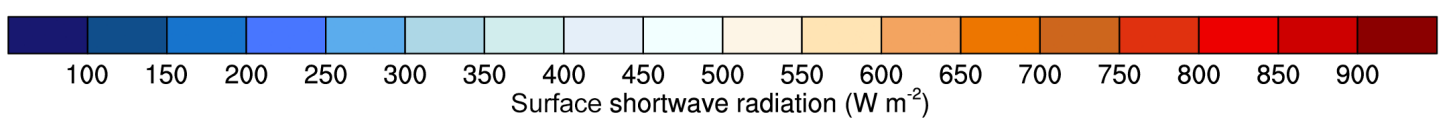

Figure 8. SIS of TT (a), FF (b) and SARAH-2 dataset by CM SAF (c) on 4 April 2014 at 12:30 UTC in Germany. Dots: SIS at SYNOP (thin circle lines) and pyranometer stations (thicker circle lines).

(a)

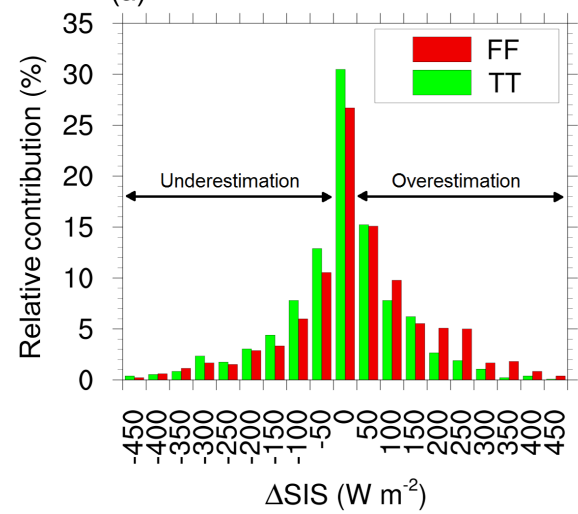

(b)

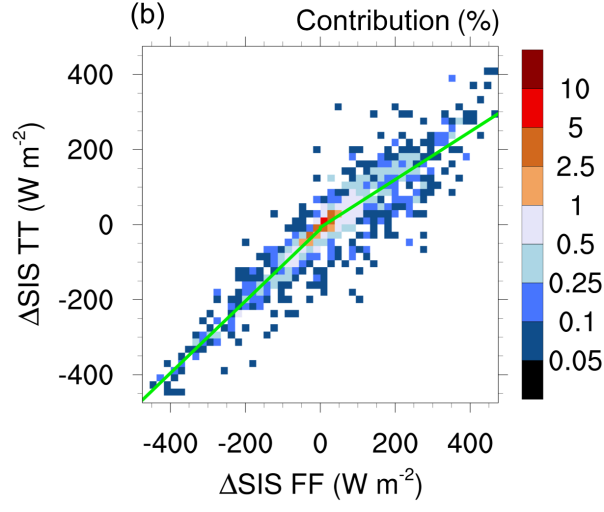

Figure 9. (a) Histogram of difference in SIS on 4 April 2014 (05:30-16:30 UTC) in Germany for FF and TT simulation relative to SYNOP station measurements (see Fig. 8). (b) Joint histogram of SIS difference on 4 April 2014 for simulations FF and TT relative to SYNOP station measurements (see Fig. 8). Green lines indicate linear regressions for the sector with negative $\Delta$ SIS FF (slope: 0.959; intersection: -12.086) and positive $\Delta$ SIS FF (slope: 0.638; intersection: -7.659).

The improvements in TT are confirmed by Fig. 9a), which shows a histogram of the differences (simulation - ground observation) for 4 April 2014 using hourly data at SYNOP stations (see Fig. 8). In case of underestimation (negative $\Delta \mathrm{SIS}$ ), the errors for TT are larger than for FF. The opposite happens in the range of overestimation (positive $\Delta$ SIS), where the error is remarkably lower for TT. Furthermore, the difference between TT and FF is larger in the overestimation sector than in the underestimation sector. This becomes even more clear in the joint histogram (Fig. 9b). When the difference is negative in the FF case, the green regression line is almost identical to the one-to-one line indicating no systematic differences between TT and FF in the underestimation sector. In the overestimation sector, however, the overestimation is strongly reduced by the TT simulation as indicated by the regression line. This finding is confirmed by Table 6 . The mean error and the SD is substantially reduced in case of TT. While the 5th percentile slightly increases in case of TT, the 95th percentile indicates that the overestimation of SIS is drastically reduced. The same holds for minimum and maximum values. In summary, this means that in the TT case, overestimations are substantially reduced compared to the FF case whereas the results remain similar for underestimations.

\subsection{PV production}

Beside the technical characteristics of the solar panels, PVpower output depends mainly on SIS, temperature and panel geometry such as orientation with respect to the sun. From that, it becomes clear that reliable day-ahead forecasts of PV power depend on accurate weather forecasts. The following 
Table 6. Statistical quantities of the distributions of $\Delta$ SIS shown in Fig. 9a.

\begin{tabular}{ccccccc}
\hline & Mean & SD & 5\% Percentile & 95\% Percentile & Min & Max \\
\hline TT & -4.45 & 125.00 & -245.80 & 188.33 & -449.90 & 444.98 \\
FF & 27.19 & 145.10 & -234.42 & 273.59 & -441.01 & 523.33 \\
\hline
\end{tabular}

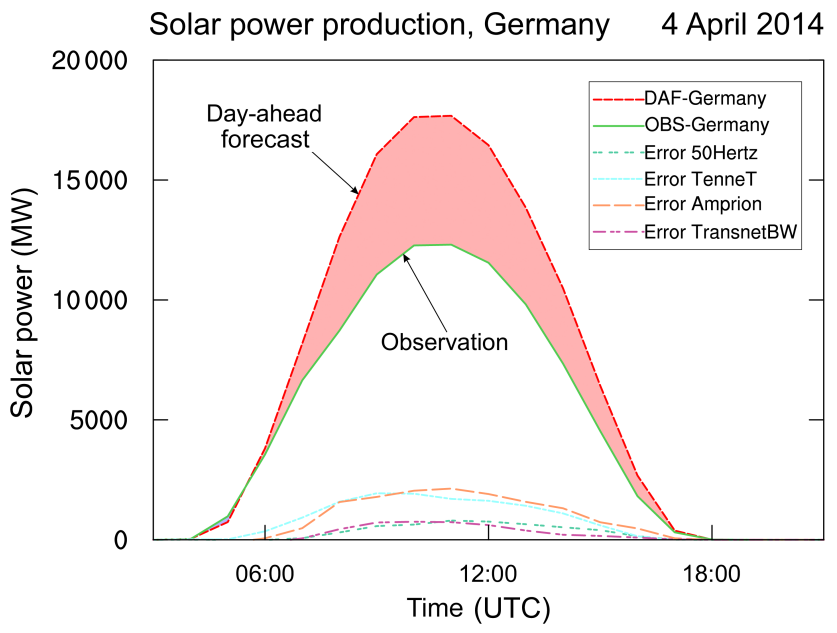

Figure 10. Time series of hourly averaged observed photovoltaic power production (green) and corresponding day-ahead forecast (red) for Germany on 4 April 2014. The red shading marks a large overestimation of up to $5.3 \mathrm{GW}$. At the bottom, the day-ahead forecast error for the four German control areas is depicted. Data source: European Energy Exchange AG (2017).

example demonstrates that the PV-power forecasts for Germany failed tremendously for 4 April 2014.

Figure 10 shows the day-ahead PV-power forecast for 4 April 2014. The illustrated day-ahead PV-power forecast is the so-called meta-forecast of the German TSOs. It is a multimodel and multi-method product, which combines many different NWP and power forecast models as well as many different post-processing methods. The day-ahead PV-power forecast for 4 April 2014 overestimated the actual power production for Germany by up to $5.3 \mathrm{GW}$. The forecast error is also divided into the control areas of the four TSOs. In the areas of TenneT and Amprion, which cover west, central and southeast Germany (see Fig. 1 of Steiner et al., 2017), the largest forecast errors occurred on 4 April 2014. These are not only the regions where large contributions of PV capacity are installed (see Fig. 1b of Köhler et al., 2017) but also the forecast of incoming solar radiation was challenged by the presence of clouds and aerosols as already discussed in Sect. 3. These discrepancies between energy demand and day-ahead forecast of supply need to be compensated, for example on the intra-day market of the European power exchange EPEX SPOT, where electricity is traded within the Austrian, French, German or Swiss transmission systems. Corresponding market data are openly pub- lished on the EEX Transparency Platform (European Energy Exchange AG, 2017). Wrong forecasts may cause economic costs on the order of tens of millions of euros per day.

The transport of Saharan dust and the interactions of mineral dust particles with the atmosphere are not explicitly considered within conventional NWP forecasts. Most likely, this has contributed to the large PV-power forecast errors on 4 April 2014 (Fig. 10). We will quantify the effect of the mineral dust outbreak on PV-power forecast for our own model results.

PV_LIB (see Sect. 2.5) is used to transfer the observed and simulated meteorological variables into normalized PV power. Computed PV power based on the observed radiation by the 26 pyranometer stations throughout Germany (see Appendix A) is taken as reference. To convert meteorological variables from the NWP simulations into PV power, the closest grid point to each pyranometer station is considered.

Figure 11 shows the observed and simulated SIS as well as normalized PV power for the stations Mannheim, Meiningen, Trier and Weihenstephan. A reduction in positive forecast error (overestimation) can be observed for the stations Mannheim, Trier and Weihenstephan. For stations with considerable cloud cover, for example Meiningen, smaller differences between the TT and FF simulations are observed. To quantify the improvement of PV-power simulations of scenario TT, Table 7 summarizes error quantities for all 26 pyranometer stations and for different lead times. For 4 April 2014, the root mean square error (RMSE) for example is reduced by about $17 \%$ from 0.124 to 0.103 . Bold values in Table 7 indicate better results and confirm that the TT simulation showed better performance with respect to the observations.

\subsection{Radiation vs. cloud microphysics}

As mentioned before, a substantial number of clouds were present on 4 April 2014. From that, the question arises of which portion of the changes we found in PV power are due to the direct aerosol effect and which are due to the indirect effect. In our case we are using a factorial method (FM) to separate the direct radiative effects from the indirect radiative effects on PV-power generation. For this purpose, an unreplicated $2^{k}$ factorial design with $k=2$ is used (Montgomery, 2008). A short description of this FM is given in Appendix B. This method was also used for other similar problems in atmospheric science (e.g., Teller and Levin, 2008; Kraut, 2015). 

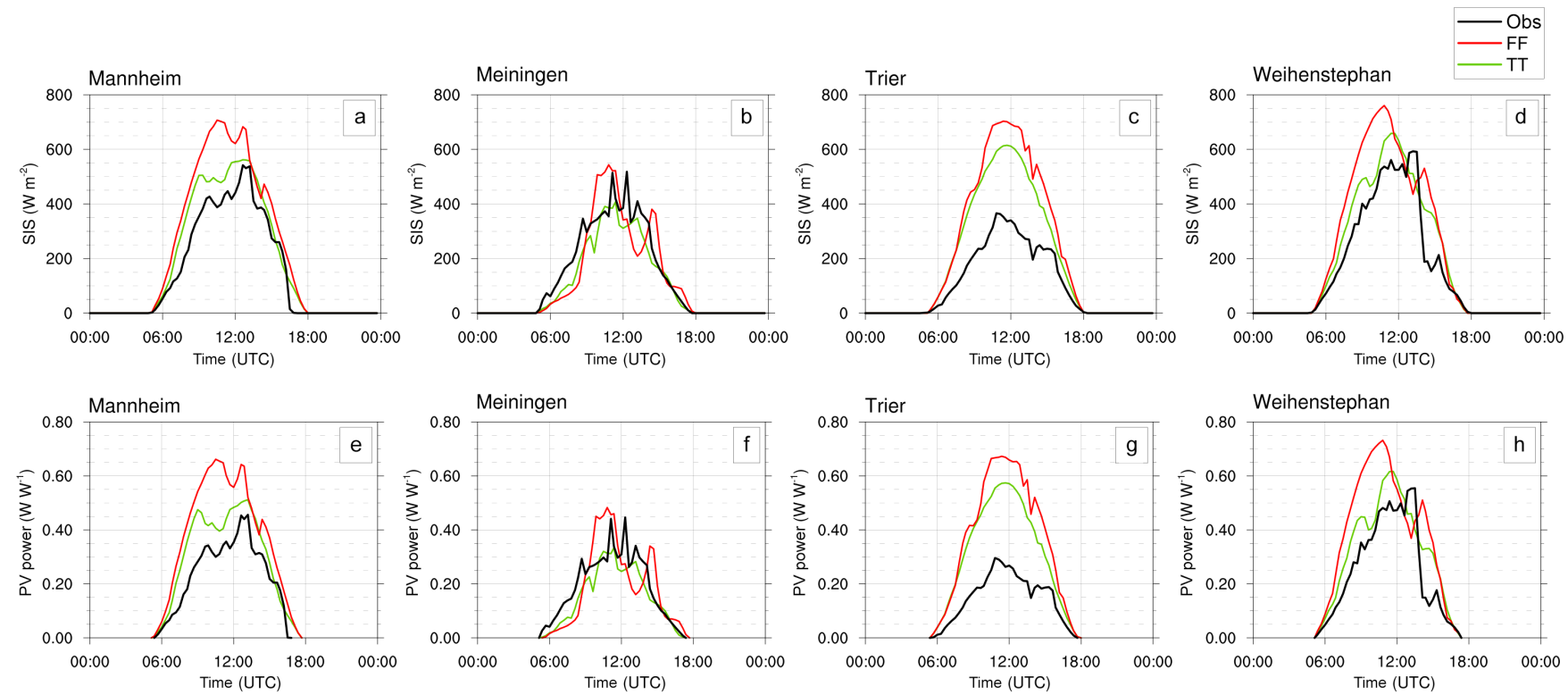

Figure 11. Comparison of observed (black, by pyranometer) and simulated (TT in green, FF in red) surface incoming shortwave irradiance (SIS, a-d) and the resulting computed normalized PV power (e-h) for the stations Mannheim, Meiningen, Trier and Weihenstephan on 4 April 2014. The normalization is done with respect to peak power.

Table 7. Statistical measures describing the quality of the simulated PV-power values using data of all 26 pyranometer stations for different lead times (3 April 2014: 0-23 h; 4 April 2014: 24-47 h; 5 April 2014: 48-72 h; 3-5 April 2014: 0-72 h). Values are given for the root mean square error (RMSE), the mean absolute error (MAE), the bias (BIAS), the SD of errors (SD) and the minimum and maximum error $\left(E_{\mathrm{min}}\right.$, $\left.E_{\max }\right)$ in $\mathrm{W} \mathrm{m}^{-2}$. Bold values mark the better simulation.

\begin{tabular}{lccccccccccccc}
\hline & \multicolumn{2}{c}{ RMSE } & \multicolumn{2}{c}{ MAE } & \multicolumn{2}{c}{ BIAS } & \multicolumn{2}{c}{ SD } & \multicolumn{2}{c}{$E_{\min }$} & \multicolumn{2}{c}{$E_{\max }$} \\
\hline Time & FF & TT & FF & TT & FF & TT & FF & TT & FF & TT & FF & TT \\
\hline 3 Apr 2014 & 0.099 & $\mathbf{0 . 0 9 2}$ & 0.049 & $\mathbf{0 . 0 4 4}$ & 0.013 & $\mathbf{0 . 0 0 6}$ & 0.099 & $\mathbf{0 0 9 2}$ & $\mathbf{- 0 . 5 3 4}$ & -0.542 & $\mathbf{0 . 5 5 4}$ & 0.563 \\
4 Apr 2014 & 0.124 & $\mathbf{0 . 1 0 3}$ & 0.059 & $\mathbf{0 . 0 4 8}$ & 0.009 & $\mathbf{- 0 . 0 0 4}$ & 0.123 & $\mathbf{0 . 1 0 3}$ & $\mathbf{- 0 . 6 6 0}$ & -0.672 & 0.546 & $\mathbf{0 . 4 4 2}$ \\
5 Apr 2014 & 0.110 & $\mathbf{0 . 0 7 9}$ & 0.054 & $\mathbf{0 . 0 4 0}$ & 0.029 & $\mathbf{0 . 0 0 3}$ & 0.106 & $\mathbf{0 . 0 7 9}$ & $\mathbf{- 0 . 4 0 5}$ & -0.418 & 0.577 & $\mathbf{0 . 4 1 8}$ \\
3-5 Apr 2014 & 0.111 & $\mathbf{0 . 0 9 2}$ & 0.054 & $\mathbf{0 . 0 4 4}$ & 0.017 & $\mathbf{0 . 0 0 1}$ & 0.110 & $\mathbf{0 . 0 9 2}$ & $\mathbf{- 0 . 6 6 0}$ & -0.672 & 0.577 & $\mathbf{0 . 5 6 3}$ \\
\hline
\end{tabular}

Figures 12 and 13 show the results of the FM calculation for four selected SYNOP stations (Mannheim, Meiningen, Trier and Weihenstephan-Duernast). The geographical positions of the stations are given in Table $\mathrm{C} 1$. The figures show the temporal evolution of the difference in normalized PV power between TT and the measurements (green line, right ordinate) and the corresponding difference between FF and the measurements (red line, right ordinate). In contours, the percentage contribution of direct radiative (beige), indirect radiative (blue) and synergistic interaction (orange) effects to the change between TT and FF based on the FM calculation is given (left ordinate).

The more westerly stations (Mannheim, Trier) show a systematic overestimation of PV-power generation in the FF case. At both stations, the PV-power forecast is improved significantly in the TT simulation. For Mannheim, the contributions of the different effects is alternating, whereas in Trier the direct radiative effect dominates the result, nearly always accounting for more than $50 \%$. In Meiningen, the contributions of the different effects vary strongly, accompanied by several intersections of the FF and TT curves. However, the green TT curve looks like a damped version of the red FF curve. For overestimations of the PV power in the FF case, the TT result is lower and for underestimations the TT result is higher, leading to a better agreement with measurements and therefore an improvement in the forecast. One could argue that the overestimations are damped mostly by direct radiative effects (e.g., at 10:00 UTC and 14:00 UTC) whereas the underestimations are damped mostly by indirect effects (e.g., at 08:00 UTC and 13:00 UTC). This becomes more obvious at Weihenstephan. Between 06:00 UTC and 11:00 UTC, the overestimation of PV power is nearly exclusively caused by direct radiative effects. Starting from 12:00 UTC, the subsequent underestimation is nearly completely related to indirect radiative and synergistic interaction effects. From 14:00 UTC on, FF shows an overestima- 

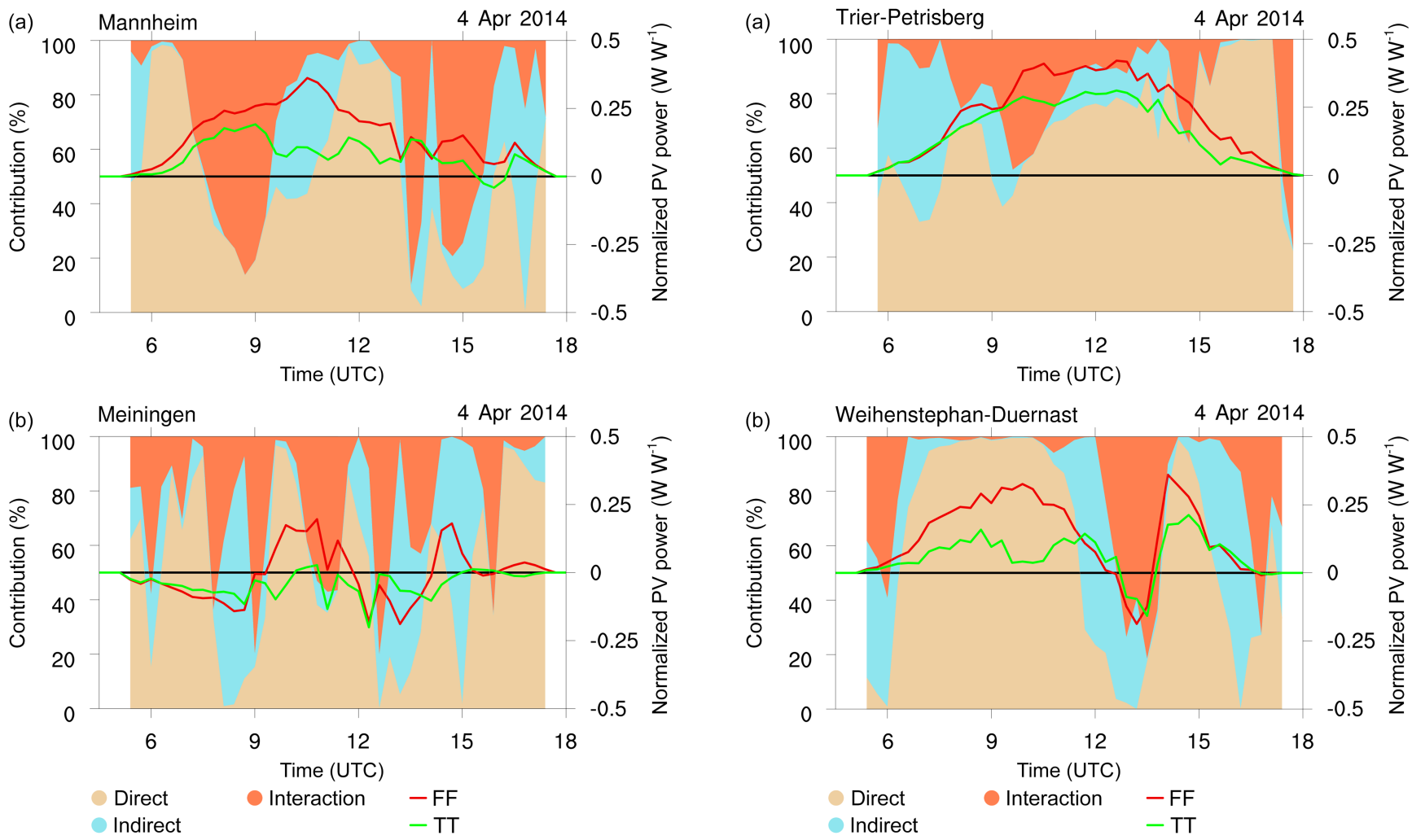

Figure 12. Temporal evolution of the difference in normalized PV power between TT and measurements (green line, right ordinate) and the corresponding difference between FF and measurements (red line, right ordinate) on 4 April 2014 at Mannheim (a) and Meiningen (b). Contours: percentaged contribution of direct radiative, indirect radiative and synergistic interaction effects to the change between TT and FF based on the FM calculation (left ordinate).

tion, whereas in the TT case the forecast is improved mostly by direct radiative effects.

The results for all SYNOP stations with high-quality radiation measurements in Germany are shown in Fig. 14. For the classification of the results at these stations, five different characteristic measures are calculated. A mathematical description of these characteristic measures is given in Appendix $\mathrm{C}$. The integrated difference $\mathcal{I D}$ is a measure for the magnitude of the difference between TT and FF without any information about the sign of the difference. The mean improvement ratio $\overline{\mathcal{I} \mathcal{R}}$ is a measure for whether the TT result is better or worse than the FF result, where $\overline{\mathcal{I} \mathcal{R}}=0$ characterizes a perfect FF result, $\overline{\mathcal{I} \mathcal{R}}=1$ a perfect TT result and $\overline{\mathcal{I R}}=0.5$ an indifferent result. Hence, $\overline{\mathcal{I} \mathcal{R}}>0.5$ shows an improvement of the results due to the impact of mineral dust on cloud formation and radiation. $\overline{\mathcal{C R}}, \overline{\mathcal{C C}}$ and $\overline{\mathcal{C I}}$ state the mean percentage contribution of direct radiative, indirect radiative and synergistic interaction effects on the difference between FF and TT. The synergistic interaction represents the nonlinear feedbacks, which are acting between the two

Figure 13. Same as Fig. 12 for Trier (a) and Weihenstephan (b).

factors direct radiative effect and indirect radiative effect, when both effects are active at the same time. The contributions of the different effects are derived by the FM formulae B1-B7 given in Appendix B.

Of the 26 stations in total, 17 show an improvement of the forecast in the TT case compared to the FF case (i.e., $\overline{\mathcal{I R}}>0.5)$. However, this includes also stations with small differences between the results of TT and FF where the significance of the measure $\overline{\mathcal{I} \mathcal{R}}$ is low as it does not contain any information about the magnitude of the change. Focussing on stations with a high difference (here defined as $\mathcal{I D}>1$ ), 14 out of 16 stations show an improvement. For very high differences (here defined as $\mathcal{I D}>2$ ), nearly every station (8 out of 9) shows improvements in the TT forecast. The only exception is Nuernberg, where there is a strong underestimation of the PV power in the early morning which is not compensated by the improved forecast afterwards (not shown). In total, the indirect effect contributes for $45.41 \%$ to this underestimation in Nuernberg. Averaging over all stations, $63.86 \%$ of the differences are caused by the direct radiative effect, whereas 20.22 and $15.92 \%$ are caused by the indirect and synergistic interaction effects, respectively. For stations with very high differences, this shifts to higher contributions of the direct effect $(68.08,16.21$ and $15.71 \%)$.

Taking a look at outlying stations, Hohenpeissenberg, Saarbruecken, Weihenstephan and Hamburg show compar- 

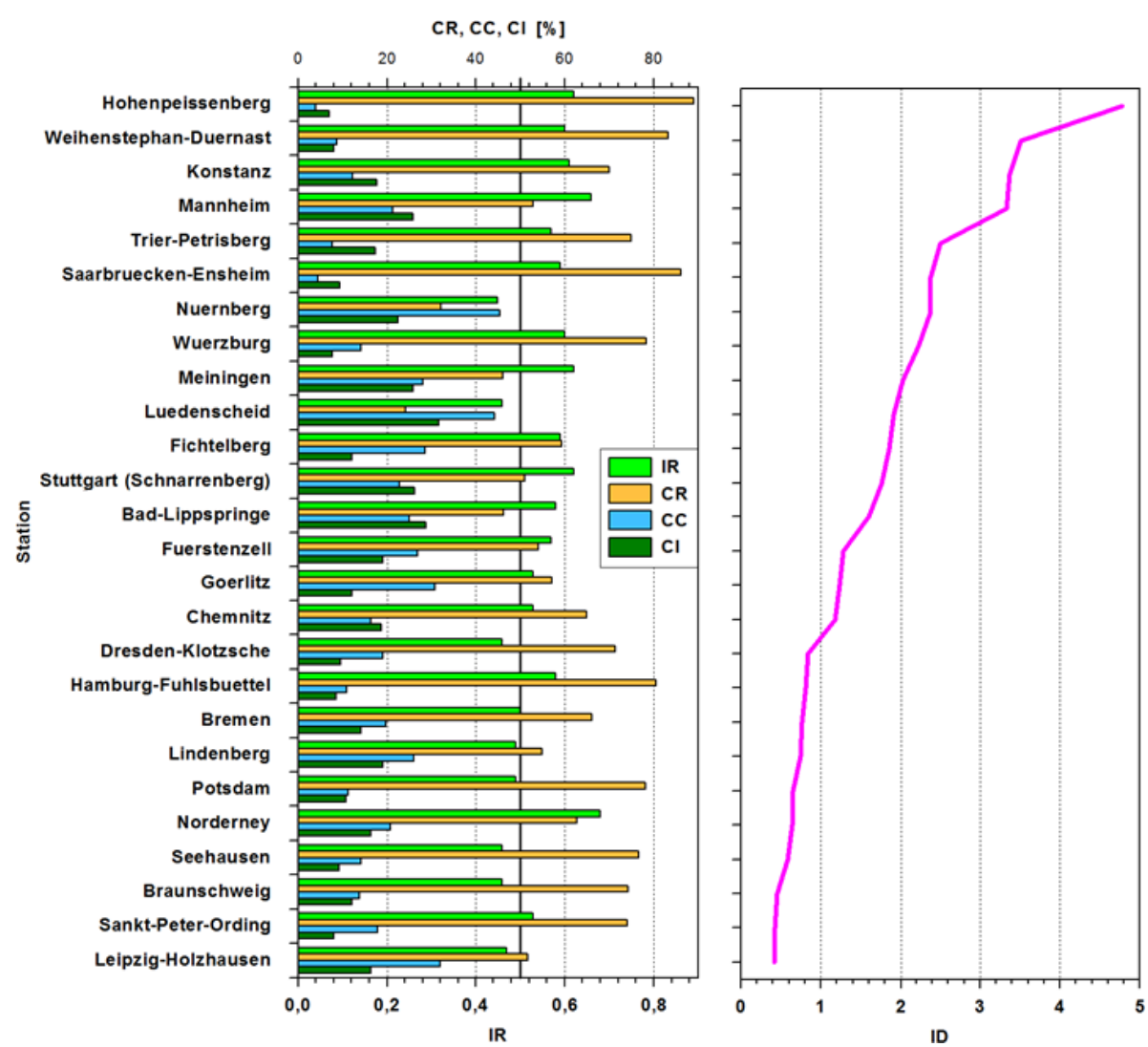

Figure 14. Visualization of the different scores described in Appendix $\mathrm{C}$ for all pyranometer stations. The stations are sorted by their $\mathcal{I D}$ score with the station with the highest score on top.

atively high contributions of the direct effect of more than $80 \%$. They have in common that, in the FF case, the PV power was nearly always overestimated. The direct effect in the TT case leads to a decrease in the PV-power forecast, which in turn leads to an improvement. At Luedenscheid and Nuernberg, indirect effects contribute more than direct effects to the changes in PV-power forecast. These are the only two stations that show a worsening of the PV-power forecast out of the 16 stations with high differences. For Luedenscheid, strong contributions of indirect and synergistic interaction effects in the afternoon lead to an overestimation of the PV power in the afternoon while the FF forecast already shows a good result (not shown). The forecast for Nuernberg in the FF case already shows a systematic underestimation of the PV power. A mixture of direct and indirect radiative effects in the morning leads to a strong further underestimation, dominating the $\overline{\mathcal{I} \mathcal{R}}$ score. The improvements mostly due to indirect and synergistic interaction effects afterwards are smaller (not shown).

\section{Conclusions}

Reliable PV-power forecast is gaining importance especially in those countries with increasing use of renewable energy as is the case in Germany. Aerosol particles have a major impact on the radiation reaching the solar panels at the ground. The aerosol concentration differs in space and time, nevertheless, most current numerical weather prediction models use climatological maps of the aerosol distribution. Thus, they are not able to account for the actual impact of aerosol particles on PV-power production. Within this study we extended the operational weather forecast model ICON-ART by including the treatment of direct and indirect effects of prognostic mineral dust. Through this, we are able to quantify PV-power forecast improvements when considering mineral dust radiative effects for a Saharan dust episode on 4 April 2014.

Compared to observations at 26 pyranometer stations, the forecast including mineral dust feedback processes strongly reduces overestimations of incoming solar radiation that exist in the forecast without mineral dust feedback. For underestimations, the results are indifferent. For $65 \%$ of the pyranometer stations, the simulated PV is in much better agreement with observations when the feedback between mineral dust, radiation and clouds is accounted for. For the period from 3 to 5 April 2014, as well as for each day individually, RMSE, mean absolute error (MAE), bias and SD are reduced in the simulation that accounts for mineral dust feedback compared to the reference simulation. For 4 April 2014, 
this results in a reduction in RMSE of $17 \%$, MAE by $19 \%$, $\mathrm{SD}$ by $16 \%$ and the bias from 0.09 to $-0.04 \mathrm{~W} \mathrm{~m}^{-2}$.

We quantify the individual contributions of the direct and indirect effect of mineral dust on PV-power forecast and find that the direct effect is most important. Eight out of nine stations with very high differences between the simulation with mineral dust feedback and the reference simulation show an improvement due to the consideration of mineral dust. For stations with high differences, we find an improvement at 14 out of 16 stations. The direct radiative effect dominates these improvements, accounting for $64 \%$ of the differences at all stations, whereas indirect effects account for $20 \%$ and synergistic interaction effects account for $16 \%$. At the stations with very high differences, even higher contributions can be attributed to the direct effect (68, 16 and $16 \%$, respectively). We also find that for our simulations, the improvement also depends on the dominating effect. This means that for stations with direct radiative effect dominating the differences, the improvement is higher than for stations with indirect effects dominating the differences. We assume that indirect effects may be superimposed by the challenge of representing complex cloud structures, independent of mineral dust availability.
Our study shows the importance of considering mineral dust in numerical weather prediction systems. Understanding and assessing the role of mineral dust in the atmosphere and in particular during special weather situations such as Saharan dust outbreaks will not only help to improve numerical weather predictions but also contribute to reliable PV-power forecasts and a safe electricity supply.

Data availability. The underlying data and model code can be obtained from the authors upon request. 
Appendix A: Pyranometer stations

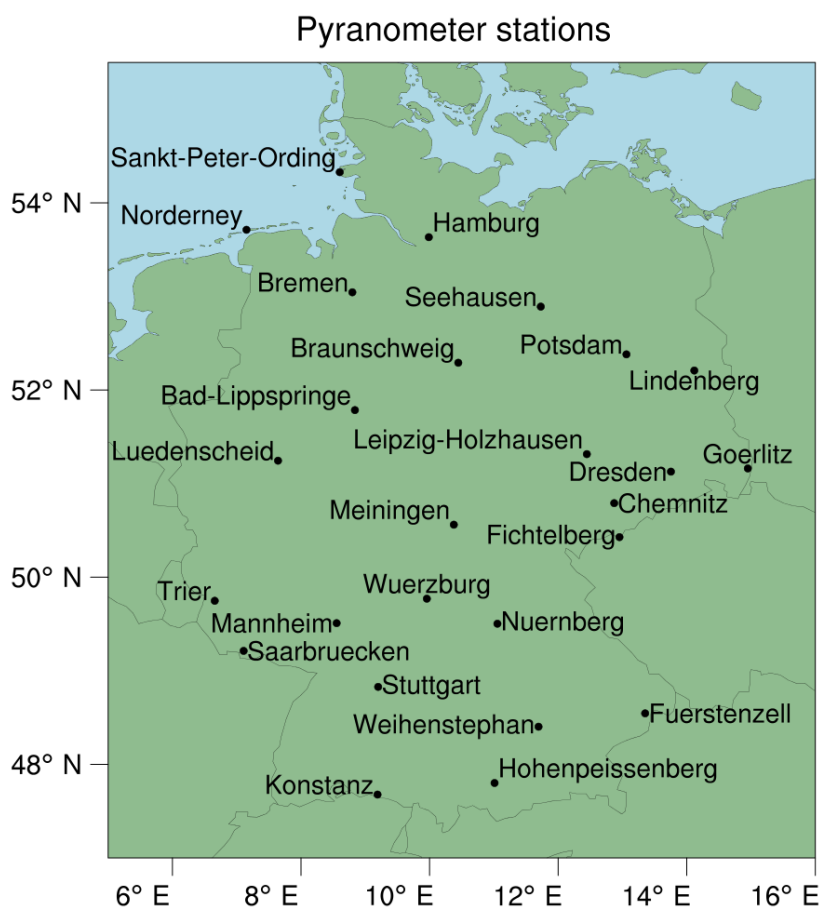

Figure A1. Positions and names of pyranometer stations in Germany.

The presented study relies on pyranometer observations of 26 stations throughout Germany. Their names, coordinates and WMO-ids are given in Table C1. Additionally, their locations are illustrated in Fig. A1. At each position, direct and diffuse radiation is measured with a measurement interval of $1 \mathrm{~min}$.

\section{Appendix B: Factorial method}

An FM is used to separate the contributions of direct and indirect radiative effects on the outcome of the PV-power forecast. A detailed description of this method is given by Montgomery (2008). Examples for the usage of this method in atmospheric sciences can be found in Teller and Levin (2008) and Kraut (2015). In our case, we are using a $2^{2}$ experiment design; i.e., we have two factors (direct and indirect effect) on two levels denoted as $\mathrm{T}$ and $\mathrm{F}$ as described in Sect. 4. The resulting PV-power forecast at a certain station of the individual cases are then denoted as $\mathcal{P} \mathcal{V}_{\mathrm{FF}}, \mathcal{P} \mathcal{V}_{\mathrm{TT}}, \mathcal{P} \mathcal{V}_{\mathrm{TF}}$ and $\mathcal{P} \mathcal{V}_{\mathrm{FT}}$, where the indices are chosen in accordance with Table 5 . The relative contribution of direct and indirect effects can be obtained by first calculating the sum of squares for each effect:

$$
\begin{aligned}
& \mathrm{SS}_{\mathrm{R}}=\frac{\left(\mathcal{P} \mathcal{V}_{\mathrm{TT}}+\mathcal{P} \mathcal{V}_{\mathrm{TF}}-\mathcal{P} \mathcal{V}_{\mathrm{FT}}-\mathcal{P} \mathcal{V}_{\mathrm{FF}}\right)^{2}}{4}, \\
& \mathrm{SS}_{\mathrm{C}}=\frac{\left(\mathcal{P} \mathcal{V}_{\mathrm{TT}}+\mathcal{P} \mathcal{V}_{\mathrm{FT}}-\mathcal{P} \mathcal{V}_{\mathrm{TF}}-\mathcal{P} \mathcal{V}_{\mathrm{FF}}\right)^{2}}{4}, \\
& \mathrm{SS}_{\mathrm{I}}=\frac{\left(\mathcal{P} \mathcal{V}_{\mathrm{TT}}+\mathcal{P} \mathcal{V}_{\mathrm{FF}}-\mathcal{P} \mathcal{V}_{\mathrm{TF}}-\mathcal{P} \mathcal{V}_{\mathrm{FT}}\right)^{2}}{4}, \\
& \mathrm{SS}_{\mathrm{T}}=\mathrm{SS}_{\mathrm{R}}+\mathrm{SS}_{\mathrm{C}}+\mathrm{SS}_{\mathrm{I}},
\end{aligned}
$$

where $S_{R}$ is the sum of squares of the direct radiative effect, $\mathrm{SS}_{\mathrm{C}}$ is the sum of squares of the indirect radiative effect and $\mathrm{SS}_{\mathrm{I}}$ the sum of squares of the synergistic interaction effect. The synergistic interaction effect considers changes to the result where both factors are $\mathrm{T}$ that do not appear in the cases where one of the factors is $\mathrm{T}$ and the other one is $\mathrm{F}$. The percentage contribution of each factor can then be derived by dividing the individual sums of squares by the total sum of squares $\mathrm{SS}_{\mathrm{T}}$ multiplied by a factor of 100 :

$$
\begin{aligned}
& \mathcal{F \mathcal { M } _ { \mathrm { R } }}=\frac{\mathrm{SS}_{\mathrm{R}}}{\mathrm{SS}_{\mathrm{T}}} \cdot 100, \\
& \mathcal{F \mathcal { M } _ { \mathrm { C } }}=\frac{\mathrm{SS}_{\mathrm{C}}}{\mathrm{SS}_{\mathrm{T}}} \cdot 100, \\
& \mathcal{F} \mathcal{M}_{\mathrm{I}}=\frac{\mathrm{SS}_{\mathrm{I}}}{\mathrm{SS}_{\mathrm{T}}} \cdot 100,
\end{aligned}
$$

where $\mathcal{F} \mathcal{M}_{\mathrm{R}}$ is the percentage contribution of direct radiative effects, $\mathcal{F} \mathcal{M}_{\mathrm{C}}$ is the percentage contribution of indirect radiative effects and $\mathcal{F} \mathcal{M}_{\mathrm{I}}$ is the percentage contribution of interaction effects.

\section{Appendix C: Characteristic measures}

The integrated difference $\mathcal{I D}$ is a measure for the magnitude of the difference between TT and FF without any information about the sign of the difference:

$\mathcal{I D}=\sum_{t}\left|\mathcal{P} \mathcal{V}_{\mathrm{TT}}(t)-\mathcal{P} \mathcal{V}_{\mathrm{FF}}(t)\right|$

where $t$ is an output timestep and $\mathcal{P} \mathcal{V}_{\mathrm{FF}}\left(\mathcal{P} \mathcal{V}_{\mathrm{TT}}\right)$ is the result for the PV-power forecast in the FF (TT) case. Values with $\mathcal{P} \mathcal{V}_{\mathrm{TT}}$ or $\mathcal{P} \mathcal{V}_{\mathrm{FF}}=0$ (i.e., night time values) are ignored for all calculations. As this measure states a magnitude of the difference but not whether the forecast is actually improved or not, a characteristic measure for the improvement of the forecast, the mean improvement ratio $\overline{\mathcal{I} \mathcal{R}}$, is introduced: 
$\overline{\mathcal{I} \mathcal{R}}$

$$
\begin{aligned}
& =\frac{1}{t_{\mathrm{tot}}} \sum_{t} \frac{\left|\mathcal{P} \mathcal{V}_{\mathrm{FF}}(t)-\mathcal{P} \mathcal{V}_{\mathrm{SYN}}(t)\right|}{\left|\mathcal{P} \mathcal{V}_{\mathrm{FF}}(t)-\mathcal{P} \mathcal{V}_{\mathrm{SYN}}(t)\right|+\left|\mathcal{P} \mathcal{V}_{\mathrm{TT}}(t)-\mathcal{P} \mathcal{V}_{\mathrm{SYN}}(t)\right|} \\
& =\frac{1}{t_{\mathrm{tot}}} \sum_{t} \mathcal{I} \mathcal{R}(t),
\end{aligned}
$$

where $\mathcal{P} \mathcal{V}_{\mathrm{SYN}}$ is the resulting PV power calculated from radiation measurements at the SYNOP station and $\mathcal{I} \mathcal{R}(t)$ is the improvement ratio at a specific output timestep. As for $\mathcal{P} \mathcal{V}_{\text {TT }}$ and $\mathcal{P} \mathcal{V}_{\mathrm{FF}}$, values of $\mathcal{P} \mathcal{V}_{\mathrm{SYN}}=0$ are ignored for the calculations. This characteristic measure is chosen in a way that

$\overline{\mathcal{I} \mathcal{R}} \rightarrow 0 \quad$ means a perfect FF forecast,

$\overline{\mathcal{I R}}<0.5$ means a worsening in TT simulation,

$\overline{\mathcal{I} R}=0.5$ means indifference between FF and TT,

$\overline{\mathcal{I R}}>0.5$ means an improvement in TT simulation,

$\overline{\mathcal{I R}} \rightarrow 1 \quad$ means a perfect TT forecast.
One of the major goals of this study is to quantify the individual contribution of the direct radiative effect, the indirect radiative effect and synergistic interaction effects on changes in the PV-power forecast. For this purpose, percentage contributions of the individual effects were calculated with an FM as outlined in Appendix B. The resulting percentage contributions $\mathcal{F} \mathcal{M}_{\mathrm{R}}, \mathcal{F} \mathcal{M}_{\mathrm{C}}$ and $\mathcal{F} \mathcal{M}_{\mathrm{I}}$ for direct radiative (index $\mathrm{R}$ ), indirect radiative (index $\mathrm{C}$ ) and interaction effects (index I) are used to constrain the contributions with characteristic measures. The mean percentage contributions of direct radiative $\overline{\mathcal{C} R}$, indirect radiative $\overline{\mathcal{C C}}$ and interaction effect $\overline{\mathcal{C I}}$ are obtained by

$$
\begin{aligned}
& \overline{\mathcal{C R}}=\frac{\sum_{t}\left|\mathcal{P} \mathcal{V}_{\mathrm{TT}}(t)-\mathcal{P} \mathcal{V}_{\mathrm{FF}}(t)\right| \cdot \mathcal{F} \mathcal{M}_{\mathrm{R}}(t)}{\mathcal{I D}}, \\
& \overline{\mathcal{C C}}=\frac{\sum_{t}\left|\mathcal{P} \mathcal{V}_{\mathrm{TT}}(t)-\mathcal{P} \mathcal{V}_{\mathrm{FF}}(t)\right| \cdot \mathcal{F} \mathcal{M}_{\mathrm{C}}(t)}{\mathcal{I D}}, \\
& \overline{\mathcal{C} \mathcal{I}}=\frac{\sum_{t}\left|\mathcal{P} \mathcal{V}_{\mathrm{TT}}(t)-\mathcal{P} \mathcal{V}_{\mathrm{FF}}(t)\right| \cdot \mathcal{F} \mathcal{M}_{\mathrm{I}}(t)}{\mathcal{I D}} .
\end{aligned}
$$

These values weight the result of the FM with the magnitude of the change caused by the individual effect. 
Table C1. Geographical position and characteristic measures as described in Appendix C for SYNOP stations with high-quality radiation measurements in Germany.

\begin{tabular}{|c|c|c|c|c|c|c|c|c|}
\hline Station & Latitude & Longitude & WMO-ID & $\mathcal{I D}$ & $\overline{\mathcal{I R}}$ & $\overline{\mathcal{C R}}$ & $\overline{\mathcal{C C}}$ & $\overline{\mathcal{C I}}$ \\
\hline Braunschweig & $52.2914^{\circ} \mathrm{N}$ & $10.4465^{\circ} \mathrm{E}$ & 10348 & 0.45 & 0.46 & 74.18 & 13.73 & 12.09 \\
\hline Bremen & $53.045^{\circ} \mathrm{N}$ & $8.7979^{\circ} \mathrm{E}$ & 10224 & 0.76 & 0.5 & 66.16 & 19.7 & 14.14 \\
\hline Bad Lippspringe & $51.7855^{\circ} \mathrm{N}$ & $8.8388^{\circ} \mathrm{E}$ & 10430 & 1.6 & 0.58 & 46.39 & 24.96 & 28.64 \\
\hline Chemnitz & $50.7913^{\circ} \mathrm{N}$ & $12.872^{\circ} \mathrm{E}$ & 10577 & 1.18 & 0.53 & 64.96 & 16.37 & 18.67 \\
\hline Dresden & $51.128^{\circ} \mathrm{N}$ & $13.7543^{\circ} \mathrm{E}$ & 10488 & 0.84 & 0.46 & 71.43 & 19 & 9.57 \\
\hline Fichtelberg & $50.4283^{\circ} \mathrm{N}$ & $12.9535^{\circ} \mathrm{E}$ & 10578 & 1.85 & 0.59 & 59.42 & 28.45 & 12.13 \\
\hline Fuerstenzell & $48.5451^{\circ} \mathrm{N}$ & $13.3531^{\circ} \mathrm{E}$ & 10895 & 1.28 & 0.57 & 54.08 & 26.9 & 19.02 \\
\hline Goerlitz & $51.1622^{\circ} \mathrm{N}$ & $14.9506^{\circ} \mathrm{E}$ & 10499 & 1.23 & 0.53 & 57.16 & 30.77 & 12.06 \\
\hline Hamburg & $53.6332^{\circ} \mathrm{N}$ & $9.9881^{\circ} \mathrm{E}$ & 10147 & 0.81 & 0.58 & 80.55 & 10.93 & 8.51 \\
\hline Hohenpeissenberg & $47.8009^{\circ} \mathrm{N}$ & $11.0108^{\circ} \mathrm{E}$ & 10962 & 4.78 & 0.62 & 88.96 & 4.06 & 6.98 \\
\hline Konstanz & $47.6774^{\circ} \mathrm{N}$ & $9.1901^{\circ} \mathrm{E}$ & 10929 & 3.37 & 0.61 & 70.01 & 12.31 & 17.68 \\
\hline Leipzig & $51.3151^{\circ} \mathrm{N}$ & $12.4462^{\circ} \mathrm{E}$ & 10471 & 0.41 & 0.47 & 51.71 & 31.89 & 16.39 \\
\hline Lindenberg & $52.2085^{\circ} \mathrm{N}$ & $14.118^{\circ} \mathrm{E}$ & 10393 & 0.74 & 0.49 & 55.03 & 25.96 & 19.02 \\
\hline Luedenscheid & $51.199^{\circ} \mathrm{N}$ & $7.629^{\circ} \mathrm{E}$ & 10418 & 1.91 & 0.46 & 24.14 & 44.26 & 31.61 \\
\hline Mannheim & $49.509^{\circ} \mathrm{N}$ & $8.5541^{\circ} \mathrm{E}$ & 10729 & 3.33 & 0.66 & 52.91 & 21.2 & 25.89 \\
\hline Meiningen & $50.5612^{\circ} \mathrm{N}$ & $10.3771^{\circ} \mathrm{E}$ & 10548 & 2.02 & 0.62 & 46.21 & 27.99 & 25.8 \\
\hline Norderney & $53.7123^{\circ} \mathrm{N}$ & $7.1519^{\circ} \mathrm{E}$ & 10113 & 0.64 & 0.68 & 62.8 & 20.79 & 16.41 \\
\hline Nuernberg & $49.503^{\circ} \mathrm{N}$ & $11.0549^{\circ} \mathrm{E}$ & 10763 & 2.38 & 0.45 & 32.12 & 45.41 & 22.47 \\
\hline Potsdam & $52.3813^{\circ} \mathrm{N}$ & $13.0622^{\circ} \mathrm{E}$ & 10379 & 0.65 & 0.49 & 78.12 & 11.19 & 10.69 \\
\hline Saarbruecken & $49.2128^{\circ} \mathrm{N}$ & $7.1077^{\circ} \mathrm{E}$ & 10708 & 2.38 & 0.59 & 86.13 & 4.42 & 9.46 \\
\hline Sankt Peter-Ording & $54.3279^{\circ} \mathrm{N}$ & $8.603^{\circ} \mathrm{E}$ & 10028 & 0.42 & 0.53 & 74.08 & 17.8 & 8.12 \\
\hline Seehausen & $52.8911^{\circ} \mathrm{N}$ & $11.7297^{\circ} \mathrm{E}$ & 10261 & 0.58 & 0.46 & 76.57 & 14.19 & 9.24 \\
\hline Stuttgart & $48.8282^{\circ} \mathrm{N}$ & $9.2^{\circ} \mathrm{E}$ & 10739 & 1.76 & 0.62 & 50.99 & 22.84 & 26.18 \\
\hline Trier & $49.7479^{\circ} \mathrm{N}$ & $6.6582^{\circ} \mathrm{E}$ & 10609 & 2.5 & 0.57 & 74.9 & 7.66 & 17.44 \\
\hline Weihenstephan & $48.4025^{\circ} \mathrm{N}$ & $11.6946^{\circ} \mathrm{E}$ & 10863 & 3.51 & 0.6 & 83.22 & 8.76 & 8.02 \\
\hline Wuerzburg & $49.7703^{\circ} \mathrm{N}$ & $9.9577^{\circ} \mathrm{E}$ & 10655 & 2.23 & 0.6 & 78.25 & 14.09 & 7.66 \\
\hline
\end{tabular}


Author contributions. BV initiated and coordinated the study. Various processes had to be incorporated into ICON-ART for this work: a mineral dust emissions scheme (DR, KD), aerosol-radiation interaction (PG, DR), aerosol-cloud interactions (DR) and cloudradiation feedback making use of ice particle numbers (HV, JF). VB, AS and JF performed the PV-power calculation. DR prepared the model simulation, which was then conducted by HV and JF. The analysis of the data and the writing of the manuscript were performed jointly by all authors in roughly equal shares.

Competing interests. The authors declare that they have no conflict of interest.

Acknowledgements. Part of this research is funded by the Federal Ministry for Economic Affairs and Energy and was conducted within the project PerduS: Photovoltaikertragsreduktion durch Saharastaub, 0325932A (English: forecasting the reduction in photovoltaic power production during Saharan dust outbreaks). The authors would like to thank the EUMETSAT Satellite Application Facility on Climate Monitoring (CM SAF) for providing the SARAH-2 radiation data. We thank the AERONET Team for the data used in this publication. We also very much appreciated the help of Florian Filipitsch concerning information on and the preprocessing of observational data. Furthermore, we want to thank Ali Hoshyaripour, Andrew Barrett and two anonymous referees for their detailed comments on the manuscript.

The article processing charges for this open-access publication were covered by a Research

Centre of the Helmholtz Association.

Edited by: Yves Balkanski

Reviewed by: two anonymous referees

\section{References}

AERONET: AErosol RObotic NETwork, Ground-based remote sensing aerosol networks established by NASA and PHOTONS, https://aeronet.gsfc.nasa.gov/new_web/publications.html, last access: 9 August 2017, 2017.

AGEE-Stat, A. E. E.-S.: Entwicklung der erneuerbaren Energien in Deutschland im Jahr 2016, Quartalsbericht, in German, on behalf of the German Federal Ministry for Economic Affairs and Energy, 2016.

Alfaro, S. C. and Gomes, L.: Modeling mineral aerosol production by wind erosion: emission intensities and aerosol size distributions in source areas, J. Geophys. Res.-Atmos., 106, 1807518084, https://doi.org/10.1029/2000JD900339, 2001.

Andrews, R. W., Stein, J. S., Hansen, C., and Riley, D.: Introduction to the open source PV_LIB for python photovoltaic system modelling package, in 40th IEEE Photovoltaic Specialist Conference, https://doi.org/10.1109/PVSC.2014.6925501, 2014

Arino, O., Bicheron, P., Achard, F., Latham, J., Witt, R., and Weber, J.-L.: The most detailed portrait of Earth, ESA Bull.-Eur. Space, 136, 25-31, 2008.
Baklanov, A., Schlünzen, K., Suppan, P., Baldasano, J., Brunner, D., Aksoyoglu, S., Carmichael, G., Douros, J., Flemming, J., Forkel, R., Galmarini, S., Gauss, M., Grell, G., Hirtl, M., Joffre, S., Jorba, O., Kaas, E., Kaasik, M., Kallos, G., Kong, X., Korsholm, U., Kurganskiy, A., Kushta, J., Lohmann, U., Mahura, A., Manders-Groot, A., Maurizi, A., Moussiopoulos, N., Rao, S. T., Savage, N., Seigneur, C., Sokhi, R. S., Solazzo, E., Solomos, S., Sørensen, B., Tsegas, G., Vignati, E., Vogel, B., and Zhang, Y.: Online coupled regional meteorology chemistry models in Europe: current status and prospects, Atmos. Chem. Phys., 14, 317-398, https://doi.org/10.5194/acp-14-317-2014, 2014.

Balkanski, Y., Schulz, M., Claquin, T., and Guibert, S.: Reevaluation of Mineral aerosol radiative forcings suggests a better agreement with satellite and AERONET data, Atmos. Chem. Phys., 7, 81-95, https://doi.org/10.5194/acp-7-81-2007, 2007.

Bangert, M.: Interaction of Aerosol, Clouds, and Radiation on the Regional Scale, Ph. D. thesis, Karlsruher Institut für Technologie (KIT), 2012.

Bangert, M., Nenes, A., Vogel, B., Vogel, H., Barahona, D., Karydis, V. A., Kumar, P., Kottmeier, C., and Blahak, U.: Saharan dust event impacts on cloud formation and radiation over Western Europe, Atmos. Chem. Phys., 12, 4045-4063, https://doi.org/10.5194/acp-12-4045-2012, 2012.

Barahona, D. and Nenes, A.: Parameterizing the competition between homogeneous and heterogeneous freezing in ice cloud formation - polydisperse ice nuclei, Atmos. Chem. Phys., 9, 59335948, https://doi.org/10.5194/acp-9-5933-2009, 2009.

Basart, S., Pérez, C., Nickovic, S., Cuevas, E., and Baldasano, J.: Development and evaluation of the BSCDREAM8b dust regional model over Northern Africa, the Mediterranean and the Middle East, Tellus B, 64, 18539, https://doi.org/10.3402/tellusb.v64i0.18539, 2012.

Benedetti, A., Morcrette, J.-J., Boucher, O., Dethof, A., Engelen, R. J., Fisher, M., Flentje, H., Huneeus, N., Jones, L., Kaiser, J. W., Kinne, S., Mangold, A., Razinger, M., Simmons, A. J., and Suttie, M.: Aerosol analysis and forecast in the European Centre for Medium-Range Weather Forecasts Integrated Forecast System: 2. Data assimilation, J. Geophys. Res.Atmos., 114, d13205, https://doi.org/10.1029/2008JD011115, 2009.

Bond, T. C., Habib, G., and Bergstrom, R. W.: Limitations in the enhancement of visible light absorption due to mixing state, J. Geophys. Res.-Atmos., 111, 1-13, https://doi.org/10.1029/2006JD007315, 2006.

Breitkreuz, H., Schroedter-Homscheidt, M., Holzer-Popp, T., and Dech, S.: Short-range direct and diffuse irradiance forecasts for solar energy applications based on aerosol chemical transport and numerical weather modeling, J. Appl. Meteorol. Clim., 48, 1766-1779, https://doi.org/10.1175/2009JAMC2090.1, 2009.

Bundesnetzagentur: Monitoringbericht 2016, https: //www.bundesnetzagentur.de/SharedDocs/Downloads/ DE/Sachgebiete/Energie/Unternehmen_Institutionen/ DatenaustauschUndMonitoring/Monitoring/ Monitoringbericht2016.pdf?_blob=publicationFile \&v=2, in German, last access: 16 March 2017, 2016.

Calinoiu, D., Paulescu, M., Ionel, I., Stefu, N., Pop, N., Boata, R., Pacurar, A., Gravila, P., Paulescu, E., and TrifTordai, G.: Influence of aerosols pollution on the amount of 
collectable solar energy, Energ. Convers. Manage., 70, 76-82, https://doi.org/10.1016/j.enconman.2013.02.012, 2013.

Casado-Rubio, J., Revuelta, M., Postigo, M., Martínez-Marco, I., and Yagüe, C.: A Postprocessing Methodology for Direct Normal Irradiance Forecasting Using Cloud Information and Aerosol Load Forecasts, J. Appl. Meteorol. Clim., 56, 1595-1608, https://doi.org/10.1175/JAMC-D-16-0297.1, 2017.

Cziczo, D. J., Froyd, K. D., Hoose, C., Jensen, E. J., Diao, M., Zondlo, M. A., Smith, J. B., Twohy, C. H., and Murphy, D. M.: Clarifying the dominant sources and mechanisms of cirrus cloud formation, Science, 340, 1320-1324, https://doi.org/10.1126/science.1234145, 2013.

Di Biagio, C., Formenti, P., Balkanski, Y., Caponi, L., Cazaunau, M., Pangui, E., Journet, E., Nowak, S., Caquineau, S., Andreae, M. O., Kandler, K., Saeed, T., Piketh, S., Seibert, D., Williams, E., and Doussin, J.-F.: Global scale variability of the mineral dust long-wave refractive index: a new dataset of in situ measurements for climate modeling and remote sensing, Atmos. Chem. Phys., 17, 1901-1929, https://doi.org/10.5194/acp17-1901-2017, 2017.

Dipankar, A., Stevens, B., Heinze, R., Moseley, C., Zängl, G., Giorgetta, M., and Brdar, S.: Large eddy simulation using the general circulation model ICON, J. Adv. Model. Earth Sy., 7, 963-986, https://doi.org/10.1002/2015MS000431, 2015.

Dubovik, O., Holben, B., Eck, Thomas Fand Smirnov, A., Kaufman, Y. J., King, M. D., Tanré, D., and Slutsker, I.: Variability of absorption and optical properties of key aerosol types observed in worldwide locations, J. Atmos. Sci., 59, 590-608, https://doi.org/10.1175/15200469(2002)059<0590:VOAAOP>2.0.CO;2, 2002.

European Energy Exchange AG: EEX Transparency Platform, https://www.eex-transparency.com/, last access: 16 March 2017, 2017.

Fécan, F., Marticorena, B., and Bergametti, G.: Parametrization of the increase of the aeolian erosion threshold wind friction velocity due to soil moisture for arid and semi-arid areas, Adv. Geosci., 17, 149-157, https://doi.org/10.1007/s00585-999-0149-7, 1998.

Flentje, H., Briel, B., Beck, C., Collaud Coen, M., Fricke, M., Cyrys, J., Gu, J., Pitz, M., and Thomas, W.: Identification and monitoring of Saharan dust: an inventory representative for south Germany since 1997, Atmos. Environ., 109, 87-96, https://doi.org/10.1016/j.atmosenv.2015.02.023, 2015.

Fouquart, Y., Bonnel, B., Brogniez, G., Buriez, J., Smith, L., Morcrette, J., and Cerf, A.: Observations of Saharan aerosols: Results of ECLATS field experiment. Part II: Broadband radiative characteristics of the aerosols and vertical radiative flux divergence, J. Appl. Meteorol. Clim., 26, 38-52, 1987.

Fu, Q., Yang, P., and Sun, W. B.: An Accurate Parameterization of the Infrared Radiative Properties of Cirrus Clouds for Climate Models, J. Climate, $11, \quad 2223-2237$, https://doi.org/10.1175/15200442(1998)011<2223:AAPOTI>2.0.CO;2, 1998.

Gasch, P., Rieger, D., Walter, C., Khain, P., Levi, Y., and Vogel, B.: An analysis of the September 2015 severe dust event in the Eastern Mediterranean, Atmos. Chem. Phys. Discuss., https://doi.org/10.5194/acp-2017-11, in review, 2017.

Gleeson, E., Toll, V., Nielsen, K. P., Rontu, L., and Mašek, J.: Effects of aerosols on clear-sky solar radiation in the ALADIN-
HIRLAM NWP system, Atmos. Chem. Phys., 16, 5933-5948, https://doi.org/10.5194/acp-16-5933-2016, 2016.

Hande, L. B., Engler, C., Hoose, C., and Tegen, I.: Seasonal variability of Saharan desert dust and ice nucleating particles over Europe, Atmos. Chem. Phys., 15, 4389-4397, https://doi.org/10.5194/acp-15-4389-2015, 2015.

Haustein, K., Pérez, C., Baldasano, J. M., Jorba, O., Basart, S., Miller, R. L., Janjic, Z., Black, T., Nickovic, S., Todd, M. C., Washington, R., Müller, D., Tesche, M., Weinzierl, B., Esselborn, M., and Schladitz, A.: Atmospheric dust modeling from meso to global scales with the online NMMB/BSC-Dust model - Part 2: Experimental campaigns in Northern Africa, Atmos. Chem. Phys., 12, 2933-2958, https://doi.org/10.5194/acp-122933-2012, 2012.

Heinze, R., Dipankar, A., Henken, C. C., Moseley, C., Sourdeval, O., Trömel, S., Xie, X., Adamidis, P., Ament, F., Baars, H., Barthlott, C., Behrendt, A., Blahak, U., Bley, S., Brdar, S., Brueck, M., Crewell, S., Deneke, H., Di Girolamo, P., Evaristo, R., Fischer, J., Frank, C., Friederichs, P., Göcke, T., Gorges, K., Hande, L., Hanke, M., Hansen, A., Hege, H.-C., Hoose, C., Jahns, T., Kalthoff, N., Klocke, D., Kneifel, S., Knippertz, P., Kuhn, A., van Laar, T., Macke, A., Maurer, V., Mayer, B., Meyer, C. I., Muppa, S. K., Neggers, R. A. J., Orlandi, E., Pantillon, F., Pospichal, B., Röber, N., Scheck, L., Seifert, A., Seifert, P., Senf, F., Siligam, P., Simmer, C., Steinke, S., Stevens, B., Wapler, K., Weniger, M., Wulfmeyer, V., Zängl, G., Zhang, D., and Quaas, J.: Large-eddy simulations over Germany using ICON: a comprehensive evaluation, Q. J. Roy. Meteor. Soc., 143, 69-100, https://doi.org/10.1002/qj.2947, 2017.

Helmert, J., Heinold, B., Tegen, I., Hellmuth, O., and Wendisch, M.: On the direct and semidirect effects of Saharan dust over Europe: A modeling study, J. Geophys. Res.-Atmos., 112, 1-24, https://doi.org/10.1029/2006JD007444, 2007.

Highwood, E. J. and Ryder, C. L.: Dust production mechanisms, in: Mineral Dust, chap. 11, edited by: Knippertz, P. and Stuut, J.B. W., Springer, Dordrecht, Netherlands, 267-286, 2014.

Hoose, C. and Möhler, O.: Heterogeneous ice nucleation on atmospheric aerosols: a review of results from laboratory experiments, Atmos. Chem. Phys., 12, 9817-9854, https://doi.org/10.5194/acp-12-9817-2012, 2012.

Inman, R. H., Pedro, H. T., and Coimbra, C. F.: Solar forecasting methods for renewable energy integration, Prog. Energ. Combust., 39, 535-576, https://doi.org/10.1016/j.pecs.2013.06.002, 2013.

Kalnay, E.: Atmospheric Modeling, Data Assimilation and Predictability, Cambridge University Press, 2003.

Kaufman, Y., Tanré, D., Dubovik, O., Karnieli, A., and Remer, L.: Absorption of sunlight by dust as inferred from satellite and ground-based remote sensing, Geophys. Res. Lett., 28, 14791482, https://doi.org/10.1029/2000GL012647, 2001.

Klein, H., Nickovic, S., Haunold, W., Bundke, U., Nillius, B., Ebert, M., Weinbruch, S., Schuetz, L., Levin, Z., Barrie, L. A., and Bingemer, H.: Saharan dust and ice nuclei over Central Europe, Atmos. Chem. Phys., 10, 10211-10221, https://doi.org/10.5194/acp-10-10211-2010, 2010.

Knippertz, P. and Stuut, J.-B. W.: Mineral Dust: A Key Player in the Earth System, Springer, 2014. 
Köhler, C., Steiner, A., Saint-Drenan, Y.-M., Ernst, D., BergmannDick, A., Zirkelbach, M., Ben Bouallègue, Z., Metzinger, I., and Ritter, B.: Critical weather situations for renewable energies Part B: Low stratus risk for solar power, Renew. Energ., 101, 794-803, https://doi.org/10.1016/j.renene.2016.09.002, 2017.

Köhler, C. G., and Seifert, A.: Identifying sensitivities for cirrus modelling using a two-moment twomode bulk microphysics scheme, Tellus B, 67, 24494, https://doi.org/10.3402/tellusb.v67.24494, 2015.

Koop, T., Luo, B., Tsias, A., and Peter, T.: Water activity as the determinant for homogeneous ice nucleation in aqueous solutions, Nature, 406, 611-614, https://doi.org/10.1038/35020537, 2000.

Köpke, P., Hess, M., Schult, I., and Shettle, E.: Global aerosol data set, Tech. rep., Max-Planck-Institut für Meteorologie, Hamburg, 44 pp., 1997.

Kraut, I.: Separating the Aerosol Effect in Case of a "Medicane", 68, KIT Scientific Publishing, 2015.

Lew, D. and Richard, P.: Western wind and solar integration study, Tech. rep., National Renewable Energy Laboratories, 2010.

Lew, D., Miller, N., Clark, K., Jordan, G., and Gao, Z.: Inpact of high solar penetration in the western interconnection, Tech. rep., National Renewable Energy Laboratories, 2010.

Lu, C.-H., da Silva, A., Wang, J., Moorthi, S., Chin, M., Colarco, P., Tang, Y., Bhattacharjee, P. S., Chen, S.-P., Chuang, H.-Y., Juang, H.-M. H., McQueen, J., and Iredell, M.: The implementation of NEMS GFS Aerosol Component (NGAC) Version 1.0 for global dust forecasting at NOAA/NCEP, Geosci. Model Dev., 9, 19051919, https://doi.org/10.5194/gmd-9-1905-2016, 2016.

Mätzler, C.: MATLAB functions for Mie scattering and absorption, version 2, Tech. rep., Institute of Applied Physics, University of Bern, 1-26, 2002.

Manders, A. M. M., Builtjes, P. J. H., Curier, L., Denier van der Gon, H. A. C., Hendriks, C., Jonkers, S., Kranenburg, R., Kuenen, J., Segers, A. J., Timmermans, R. M. A., Visschedijk, A., Wichink Kruit, R. J., Van Pul, W. A. J., Sauter, F. J., van der Swaluw, E., Swart, D. P. J., Douros, J., Eskes, H., van Meijgaard, E., van Ulft, B., van Velthoven, P., Banzhaf, S., Mues, A., Stern, R., Fu, G., Lu, S., Heemink, A., van Velzen, N., and Schaap, M.: Curriculum Vitae of the LOTOS-EUROS (v2.0) chemistry transport model, Geosci. Model Dev. Discuss., https://doi.org/10.5194/gmd-2017-88, in review, 2017.

Manders-Groot, A., Segers, A., and Jonkers, S.: LOTOS-EUROS v2.0 reference guide, TNO report, 2016.

Marticorena, B. and Bergametti, G.: Modeling the atmospheric dust cycle: 1. Design of a soil-derived dust emission scheme, J. Geophys. Res.-Atmos., 100, 16415-16430, https://doi.org/10.1029/95JD00690, 1995.

McConnell, C. L., Formenti, P., Highwood, E. J., and Harrison, M. A. J.: Using aircraft measurements to determine the refractive index of Saharan dust during the DODO Experiments, Atmos. Chem. Phys., 10, 3081-3098, https://doi.org/10.5194/acp10-3081-2010, 2010.

Mie, G.: Beiträge zur Optik trüber Medien, speziell kolloidaler Metallösungen, Ann. Phys., 330, 377-445, https://doi.org/10.1002/andp.19083300302, 1908.

Mlawer, E. J., Taubman, S. J., Brown, P. D., Iacono, M. J., and Clough, S. A.: Radiative transfer for inhomogeneous atmospheres: RRTM, a validated correlated-k model for the longwave, J. Geophys. Res.-Atmos., 102, 16663-16682, https://doi.org/10.1029/97JD00237, 1997.

Montgomery, D. C.: Design and analysis of experiments, John Wiley and Sons, 2008.

Morcrette, J.-J., Boucher, O., Jones, L., Salmond, D., Bechtold, P., Beljaars, A., Benedetti, A., Bonet, A., Kaiser, J. W., Razinger, M., Schulz, M., Serrar, S., Simmons, A. J., Sofiev, M., Suttie, M., Tompkins, A. M., and Untch, A.: Aerosol analysis and forecast in the European Centre for Medium-Range Weather Forecasts Integrated Forecast System: Forward modeling, J. Geophys. Res.-Atmos., 114, 1-17, https://doi.org/10.1029/2008JD011235, 2009.

Moulin, C., Gordon, H. R., Banzon, V. F., and Evans, R. H.: Assessment of Saharan dust absorption in the visible from SeaWiFS imagery, J. Geophys. Res.-Atmos., 106, 18239-18249, https://doi.org/10.1029/2000JD900812, 2001.

Mueller, R., Pfeifroth, U., and Traeger-Chatterjee, C.: Towards optimal aerosol information for the retrieval of solar surface radiation using Heliosat, Atmosphere, 6, 863-878, https://doi.org/10.3390/atmos6070863, 2015.

Myhre, G. and Stordal, F.: Global sensitivity experiments of the radiative forcing due to mineral aerosols, J. Geophys. Res.-Atmos., 106, 18193-18204, 2001.

Nachtergaele, F. and Batjes, N.: Harmonized world soil database, FAO, 2012.

Nickovic, S., Kallos, G., Papadopoulos, A., and Kakaliagou, O.: A model for prediction of desert dust cycle in the atmosphere, J. Geophy. Res.-Atmos., 106, 18113-18129, https://doi.org/10.1029/2000JD900794, 2001.

Nikitidou, E., Kazantzidis, A., and Salamalikis, V.: The aerosol effect on direct normal irradiance in Europe under clear skies, Renew. Energ., 68, 475-484, https://doi.org/10.1016/j.renene.2014.02.034, 2014.

Nowottnick, E., Colarco, P., da Silva, A., Hlavka, D., and McGill, M.: The fate of saharan dust across the atlantic and implications for a central american dust barrier, Atmos. Chem. Phys., 11, 8415-8431, https://doi.org/10.5194/acp-11-8415-2011, 2011.

Papayannis, A., Amiridis, V., Mona, L., Tsaknakis, G., Balis, D., Bösenberg, J., Chaikovski, A., De Tomasi, F., Grigorov, I., Mattis, I., Mitev, V., Müller, D., Nickovic, S., Pérez, C., Pietruczuk, A., Pisani, G., Ravetta, F., Rizi, V., Sicard, M., Trickl, T., Wiegner, M., Gerding, M., Mamouri, R. E., D'Amico, G., and Pappalardo, G.: Systematic lidar observations of Saharan dust over Europe in the frame of EARLINET (2000-2002), J. Geophys. Res.-Atmos., 113, D10204, https://doi.org/10.1029/2007JD009028, 2008.

Pérez, C., Nickovic, S., Baldasano, J. M., Sicard, M., Rocadenbosch, F., and Cachorro, V. E.: A long Saharan dust event over the western Mediterranean: Lidar, sun photometer observations, and regional dust modeling, J. Geophys. Res.-Atmos., 111, D15214, https://doi.org/10.1029/2005JD006579, 2006.

Pérez, C., Haustein, K., Janjic, Z., Jorba, O., Huneeus, N., Baldasano, J. M., Black, T., Basart, S., Nickovic, S., Miller, R. L., Perlwitz, J. P., Schulz, M., and Thomson, M.: Atmospheric dust modeling from meso to global scales with the online NMMB/BSC-Dust model - Part 1: Model description, annual simulations and evaluation, Atmos. Chem. Phys., 11, 1300113027, https://doi.org/10.5194/acp-11-13001-2011, 2011. 
Perry, M. and Troccoli, A.: Impact of a fire burn on solar irradiance and PV power, Sol. Energy., 114, 167-173, https://doi.org/10.1016/j.solener.2015.01.005, 2015.

Petzold, A., Rasp, K., Weinzierl, B., Esselborn, M., Hamburger, T., Dörnbrack, A., Kandler, K., Schütz, L., Knippertz, P., Fiebig, M., and Virkkula, A.: Saharan dust absorption and refractive index from aircraft-based observations during SAMUM 2006, Tellus B, 61, 118-130, https://doi.org/10.1111/j.16000889.2008.00383.x, 2009.

Pfeifroth, U., Kothe, S., Müller, R., Cremer, R., Trentmann, J., and Hollmann, R.: Surface Solar Radiation Data Set - Heliosat (SARAH) - Edition 2, Satellite Application Facility on Climate Monitoring, Tech. Rep. 2, EUMETSAT Satellite Application Facility on Climate Monitoring (CM SAF), https://doi.org/10.5676/EUM_SAF_CM/SARAH/V002, 2017.

Phillips, V. T., Demott, P. J., Andronache, C., Pratt, K. A., Prather, K. A., Subramanian, R., and Twohy, C.: Improvements to an empirical parameterization of heterogeneous ice nucleation and its comparison with observations, J. Atmos. Sci., 70, 378409, https://doi.org/10.1175/JAS-D-12-080.1, 2013.

Raupach, M.: Dry deposition of gases and particles to vegetation, Clean Air, 27, 200, 1993.

Rieger, D., Bangert, M., Bischoff-Gauss, I., Förstner, J., Lundgren, K., Reinert, D., Schröter, J., Vogel, H., Zängl, G., Ruhnke, R., and Vogel, B.: ICON-ART 1.0 - a new online-coupled model system from the global to regional scale, Geosci. Model Dev., 8, 1659-1676, https://doi.org/10.5194/gmd-8-1659-2015, 2015.

Sayyah, A., Horenstein, M. N., and Mazumder, M. K.: Energy yield loss caused by dust deposition on photovoltaic panels, Sol. Energy, 107, 576-604, https://doi.org/10.1016/j.solener.2014.05.030, 2014.

Schroedter-Homscheidt, M., Benedetti, A., and Killius, N.: Verification of ECMWF and ECMWF/MACC's global and direct irradiance forecasts with respect to solar electricity production forecasts, Meteorol. Z., 26, 1-19, https://doi.org/10.1127/metz/2016/0676, 2016.

Seifert, A., and Beheng, K.: A two-moment cloud microphysics parameterization for mixed-phase clouds. Part 1: Model description, Meteorol. Atmos. Phys., 92, 45-66, https://doi.org/10.1007/s00703-005-0112-4, 2006.

Shao, Y.: A model for mineral dust emission, J. Geophys. Res.-Atmos., 106, 20239-20254, https://doi.org/10.1029/2001JD900171, 2001.

Shao, Y. and Lu, H.: A simple expression for wind erosion threshold friction velocity, J. Geophys. Res.-Atmos., 105, 22437-22443, https://doi.org/10.1029/2000JD900304, 2000.

Shao, Y., Fink, A. H., and Klose, M.: Numerical simulation of a continental-scale Saharan dust event, J. Geophys. Res.-Atmos., 115, D13205, https://doi.org/10.1029/2009JD012678, 2010.

Shao, Y., Wyrwoll, K.-H., Chappell, A., Huang, J., Lin, Z., McTainsh, G. H., Mikami, M., Tanaka, T. Y., Wang, X., and Yoon, S.: Dust cycle: An emerging core theme in Earth system science, Aeolian Res., 2, 181-204, https://doi.org/10.1016/j.aeolia.2011.02.001, 2011.

Spyrou, C., Mitsakou, C., Kallos, G., Louka, P., and Vlastou, G.: An improved limited area model for describing the dust cycle in the atmosphere, J. Geophys. Res.-Atmos., 115, 1-19, https://doi.org/10.1029/2009JD013682, 2010.
Stanelle, T., Vogel, B., Vogel, H., Bäumer, D., and Kottmeier, C.: Feedback between dust particles and atmospheric processes over West Africa during dust episodes in March 2006 and June 2007, Atmos. Chem. Phys., 10, 10771-10788, https://doi.org/10.5194/acp-10-10771-2010, 2010.

Steiner, A., Köhler, C., Metzinger, I., Braun, A., Zirkelbach, M., Ernst, D., Tran, P., and Ritter, B.: Critical weather situations for renewable energies - Part A: Cyclone detection for wind power, Renew. Energ., 101, 41-50, https://doi.org/10.1016/j.renene.2016.08.013, 2017.

Stevens, B., Giorgetta, M., Esch, M., Mauritsen, T., Crueger, T., Rast, S., Salzmann, M., Schmidt, H., Bader, J., Block, K., Brokopf, R., Fast, I., Kinne, S., Kornblueh, L., Lohmann, U., Pincus, R., Reichler, T., and Roeckner, E.: Atmospheric component of the MPI-M Earth System Model: ECHAM6, J. Adv. Model. Earth Sy., 5, 146-172, https://doi.org/10.1002/jame.20015, 2013.

Teller, A. and Levin, Z.: Factorial method as a tool for estimating the relative contribution to precipitation of cloud microphysical processes and environmental conditions: Method and application, J. Geophys. Res.-Atmos., 113, D02202, https://doi.org/10.1029/2007JD008960, 2008.

Vautard, R., Bessagnet, B., Chin, M., and Menut, L.: On the contribution of natural Aeolian sources to particulate matter concentrations in Europe: Testing hypotheses with a modelling approach, Atmos. Environ., 39, 3291-3303, https://doi.org/10.1016/j.atmosenv.2005.01.051, 2005.

Vogel, B., Hoose, C., Vogel, H., and Kottmeier, C.: A model of dust transport applied to the Dead Sea Area, Meteorol. Z., 15, 611624, https://doi.org/10.1127/0941-2948/2006/0168, 2006.

Voigt, C., Schumann, U., Minikin, A., Abdelmonem, A., Afchine, A., Borrmann, S., Boettcher, M., Buchholz, B., Bugliaro, L., Costa, A., et al.: ML-CIRRUS - The airborne experiment on natural cirrus and contrail cirrus with the high-altitude long-range research aircraft HALO, B. Am. Meteorol. Soc., 271-288, https://doi.org/10.1175/BAMS-D-1500213.1, 2016.

Volz, F. E.: Infrared refractive index of atmospheric aerosol substances, Appl. Optics, 11, 755-759, 1972.

Volz, F. E.: Infrared optical constants of ammonium sulfate, Sahara dust, volcanic pumice, and flyash, Appl. Optics, 12, 564-568, 1973.

White, B. R.: Soil transport by winds on Mars, J. Geophys. Res.-Sol. Ea., 84, 4643-4651, https://doi.org/10.1029/JB084iB09p04643, 1979.

Wirth, H.: Aktuelle Fakten zur Photovoltaik in Deutschland, Fraunhofer ISE, in German, 2017.

Woodward, S.: Modeling the atmospheric life cycle and radiative impact of mineral dust in the Hadley Centre climate model, J. Geophys. Res.-Atmos., 106, 18155-18166, https://doi.org/10.1029/2000JD900795, 2001.

Woodward, S.: Mineral Dust in HadGEM2, Met Office, Hadley Centre Technical Note, 87, 2011.

World Meteorological Organization (WMO) Sand and Dust Storm Warning Advisory and Assessment System (SDS-WAS): The SDS-WAS programme at WMO, https://www.wmo.int/pages/ prog/arep/wwrp/new/Sand_and_Dust_Storm.html, last access: 11 August 2017, 2017.

Zängl, G., Reinert, D., Rípodas, P., and Baldauf, M.: The ICON (ICOsahedral Non-hydrostatic) modelling framework 
of DWD and MPI-M: Description of the non-hydrostatic dynamical core, Q. J. Roy. Meteor. Soc., 141, 563-579, https://doi.org/10.1002/qj.2378, 2015.

Zaihidee, F. M., Mekhilef, S., Seyedmahmoudian, M., and Horan, B.: Dust as an unalterable deteriorative factor affecting PV panel's efficiency: Why and how, Renew. Sust. Energ. Rev., 65, 1267-1278, https://doi.org/10.1016/j.rser.2016.06.068, 2016.
Zender, C. S., Bian, H., and Newman, D.: Mineral Dust Entrainment and Deposition (DEAD) model: Description and 1990s dust climatology, J. Geophys. Res.-Atmos., 108, 4416, https://doi.org/10.1029/2002JD002775, 2003. 